\title{
Spatially Enabled Web Application for Urban Cultural Heritage Monitoring and Metrics Reporting for the SDGs
}

\author{
Sevasti Chalkidou ${ }^{1, *(\mathbb{D}}$, Apostolos Arvanitis ${ }^{2}$, Petros Patias ${ }^{1}$ (D) and Charalampos Georgiadis ${ }^{3}$ \\ 1 Laboratory of Photogrammetry and Remote Sensing (PERS Lab), School of Rural and Surveying Engineering, \\ Aristotle University of Thessaloniki, 54124 Thessaloniki, Greece; patias@topo.auth.gr \\ 2 Laboratory of Cadastre and Geographic Information Systems, School of Rural and Surveying Engineering, \\ Aristotle University of Thessaloniki, 54124 Thessaloniki, Greece; aarvanit@topo.auth.gr \\ 3 School of Civil Engineering, Aristotle University of Thessaloniki, 54124 Thessaloniki, Greece; \\ harrisg@civil.auth.gr \\ * Correspondence: schalkidou@topo.auth.gr; Tel.: +30-2310-996-129
}

\section{check for} updates

Citation: Chalkidou, S.; Arvanitis, A.; Patias, P.; Georgiadis, C. Spatially Enabled Web Application for Urban Cultural Heritage Monitoring and Metrics Reporting for the SDGs. Sustainability 2021, 13, 12289. https:/ / doi.org/10.3390/su132112289

Academic Editors: Luis Javier Sánchez-Aparicio, Miguel Angel Maté-González and Diego González-Aguilera

Received: 24 September 2021 Accepted: 4 November 2021 Published: 7 November 2021

Publisher's Note: MDPI stays neutral with regard to jurisdictional claims in published maps and institutional affiliations.

Copyright: (c) 2021 by the authors. Licensee MDPI, Basel, Switzerland. This article is an open access article distributed under the terms and conditions of the Creative Commons Attribution (CC BY) license (https:// creativecommons.org/licenses/by/ $4.0 /)$.

\begin{abstract}
UNESCO and the United Nations have recently identified cultural heritage $(\mathrm{CH})$ as a key enabler of sustainability by incorporating it into several Sustainable Development Goals (SDGs). Accurate and efficient reporting on $\mathrm{CH}$ is considered fundamental despite known limitations due to the lack of sufficient and harmonized data. This paper presents a spatially enabled web application for urban $\mathrm{CH}$ monitoring for the city of Thessaloniki in Northern Greece. The objective was to integrate the information provided by several independent public registries on $\mathrm{CH}$ into a common 2D mapping and reporting platform and to enrich it with additional data provided by other built environment agencies. An estimation of the expected cost for the structural evaluation by experts of the city's CH assets was also implemented for SDG's Indicator 11.4.1. The methodology involved stakeholder identification, data collection and pre-processing, field verification and documentation, calculation of Indicator 11.4.1, and the actual coding process. The application can be found online, providing useful insights and statistical information on the city's heritage in a dashboard format. The key challenges included the lack of updated data, the existence of several individual registries, and the need for regular field inspection due to the rapidly changing urban fabric.
\end{abstract}

Keywords: cultural heritage; dashboard monitoring; sustainable development goals; heritage management; geoinformatics; web GIS; heritage reporting; Thessaloniki

\section{Introduction}

Cultural heritage $(\mathrm{CH})$ has been defined by UNESCO as 'a product and a process, which provides societies with a wealth of resources that are inherited from the past, created in the present and bestowed for the benefit of future generations' [1] (p. 130). CH can be divided into two main categories: (a) tangible $\mathrm{CH}$ assets which can be further divided into movable $\mathrm{CH}$ (e.g., paintings, sculptures, coins, manuscripts), immovable $\mathrm{CH}$ (e.g., monuments, archaeological sites et al.), and underwater cultural heritage (e.g., shipwrecks, underwater ruins, and cities), and (b) intangible $\mathrm{CH}$ which consists of oral traditions, performing arts, rituals, etc. $\mathrm{CH}$ can provide identity, character, and a sense of place in each country and community, thus enabling the easier integration of new populations in the area [2]. In the case of immovable $\mathrm{CH}$ assets, which will be the prime concern of the present research, it creates landmarks in the urban fabric and showcases the city's historic evolution.

$\mathrm{CH}$ presents some key intrinsic characteristics concerning its monitoring and protection. Firstly, it is a highly multidisciplinary and fragmented field that involves both technical and non-technical professionals including archaeologists, architects, surveyors, structural engineers, art restorers, urban planners, public policy officers, etc. Therefore, a 
common language and platform for communication and exchange of data between these professionals needs to be established, starting at a local level.

Each $\mathrm{CH}$ asset also presents unique characteristics, thus creating limitations in the efforts to standardize processes and methodologies regarding data collection, documentation, restoration, etc. Recent studies have tried to illustrate the problem and propose a path towards data harmonization, database interoperability [3,4], and the standardization of $\mathrm{CH}$ integration in various spatial policy documents [5]. The "INSPIRE data specification on Protected Sites-Technical Guidelines" document aims at providing a common framework for all EU countries to report homogeneous data on protected sites ( $\mathrm{CH}$ being one category of them); however, as stated in the document itself "a simple application schema is included within the Protected Sites data specification, containing a very limited set of fundamental attributes, including geometry, identifier, name, and legal foundation date and document reference" [6] (p. VII). Other researchers have tried to build on CityGML's application domain extension (ADE) to construct specific plugins related to the 3D documentation of $\mathrm{CH}$ through the extension of the Building Module [7-10]. Standardization is, in any case, crucial for adopting a more universal approach to $\mathrm{CH}$ monitoring and effectively reducing all related costs. It is also paramount considering the major technological advances of recent years and the plethora of available documentary data provided by the use of terrestrial laser scanners [11], UAVs [12], mobile or airborne lidar sensors [13,14], remote sensing [15], etc.

The sensitivity and susceptibility of $\mathrm{CH}$ assets to risks of a different nature also need to be considered. Such risks include:

1. Earthquakes and seismic activity in general, with typical examples including recent events in Italy [16] and Iran [17]. It is estimated that $16 \%$ of the listed UNESCO's World Heritage Sites are located in highly seismic zones, and 34\% are located in moderately seismic zones [17].

2. Environmental and atmospheric pollution, specifically in urban areas, that leads to the rapid degradation of the $\mathrm{CH}$ assets' facades and materials [18].

3. Hydrometeorological hazards related to climate change such as extensive fluvial or flash floods, with more recent events including 2002, 2006, 2009, and 2013 floods in Central Europe (Czech Republic, Austria, Hungary, Germany, etc.), where extensive damage was caused to several $\mathrm{CH}$ sites, such as material degradation, structural damage, etc. $[19,20]$.

4. Armed conflicts, terrorist attacks, and subsequent illicit trafficking of historic artifacts [21-23].

The most important and universal threat to tangible $\mathrm{CH}$ assets, however, remains time itself, as the vast majority of them have well overpassed the nominal life of an ordinary new structure, which is set by EC8-3 [24] at 50 years. Restorative interventions are thus necessary at regular intervals and even these need to be considered as having a nominal life within which a specific performance level can be guaranteed [25]. In that respect, registering and monitoring the type and life span of performed interventions seems imperative. The achievement of balance between the acceptable structural performance of a heritage building that will ensure the well-being of its occupants and the minimum intervention possible in the building itself is also important [26]. In general, all interventions in listed $\mathrm{CH}$ buildings need to respect the principles of reversibility and legibility, i.e., any modification should be able to be restored to its original state and condition (based on the existing documentary evidence), and newer additions should be clearly distinguished from older parts of the building [2].

In 2013, UNESCO through the "Hangzhou Declaration" stated that "culture should be considered as a fundamental enabler of sustainability" and should be integrated as an essential parameter in all future development policies and programs [27]. The above declaration was reinforced in 2015 with the introduction of the 17 Sustainable Development Goals (SDGs) by the United Nations (U.N) General Assembly [28], in which cultural heritage $(\mathrm{CH})$ was referenced explicitly or indirectly in several goals and targets. 
Target 11.4 "Strengthen efforts to protect and safeguard the world's cultural and natural heritage" of the SDG 11 "Make cities inclusive, safe, resilient and sustainable" sets the preservation of $\mathrm{CH}$ as an ad-hoc component of a sustainable urban settlement. Target 11.4 is the only target explicitly related to $\mathrm{CH}$. However, other goals and targets incorporate a $\mathrm{CH}$ aspect, such as Target 4.7 (promotion of knowledge and skills for the appreciation of cultural diversity and culture's contribution to sustainable development), Targets 8.9 and 12.b (sustainable tourism for the promotion of local culture), Target 14.7 (promotion of aquaculture) and Targets 16.3, 16.8, and 16.b (promotion of global governance and justice) [29]. UNESCO, in its "Thematic Indicators for Culture in the 2030 Agenda" report, identified even more targets that can be linked to $\mathrm{CH}$, providing evidence on the role that culture can play in transforming our societies [30]. These targets were grouped into four thematic areas, corresponding to the three pillars of sustainability (i.e., economy, environment, society), and also incorporating education and knowledge in $\mathrm{CH}$ as well [30].

Each of the SDGs Targets is accompanied by one or even several proposed indicators aiming at quantifying and monitoring the progress and efficiency of each country's policies and actions towards sustainable development in the specific domain; in this case, $\mathrm{CH}$ preservation [31]. These indicators were gradually developed by UNESCO's Institute of Statistics (UIS) to provide evidence-based results for policies and actions across different countries and levels of governance [30]. The guiding principles for $\mathrm{CH}$-related indicators were set in the "Thematic Indicators for Culture in the 2030 Agenda" as follows:

1. Rely as much as possible on existing data sources.

2. Use qualitative and quantitative data to assess the contribution of culture.

3. Integrate data from reporting on UNESCO Culture Conventions and Programmes.

4. Develop instruments to measure culture at a national and urban level.

5. Prioritize capacity building of relevant agencies.

6. Facilitate cooperation across institutions.

7. Propose a framework adaptable to different statistical capacities.

8. Provide an aspirational tool for all rather than normative assessment [30].

Target 11.4's unique indicator (Indicator 11.4.1) is focused on 'the total per capita expenditure on the preservation, protection, and conservation of all cultural and natural heritage, by the source of funding (public, private), type of heritage (cultural, natural) and level of government (national, regional and local/municipal)' [31]. Indicator 11.4.1 is challenging in terms of conceptualization and quantification for reasons that are inherent to $\mathrm{CH}$ and its management. Firstly, objections have been reported about whether it adequately reflects the mandate of Target 11.4, as the financial aspect of $\mathrm{CH}$ is only a small part of its contribution to society and the urban fabric [32]. In purely mathematical terms, Indicator 11.4.1 is sensitive to the total population of each country, as well as its annual fiscal and economic situation [33]. Moreover, it reduces the target to a single number, which perhaps in a time-series analysis can provide a per-country trend, but it does not facilitate horizontal comparisons between different countries [33]. Indeed, since the SDGs regard a global scale and need to be implemented by all UN member states, there must be some sort of benchmarking as $\mathrm{CH}$ resources vary significantly from one country to another. A clear example of this argument is that countries like Italy, Greece, Turkey, and Iran have numerous $\mathrm{CH}$ sites of different historic periods and are also susceptible to large-scale earthquakes. In that respect, it should be expected that their expenditure on the protection and preservation of $\mathrm{CH}$ is far more significant than that of other countries that do not share the same characteristics. UNESCO confirmed in its latest reports that $\mathrm{CH}$ indicators should be perhaps more appropriately used to provide time-series of data for the same place rather than attempt more generalized and global performance comparisons against absolute values benchmarks [30].

Additional pitfalls and limitations of Indicator 11.4.1 have been broadly acknowledged over the past years even by UIS itself and include such topics as inadequate disaggregation of available data (e.g., by type of heritage, levels of government, type of funding, etc.), national accounting frameworks that do not provide clear distinctions between heritage 
assets, double entries of expenditure in different levels of government [30], the need for combining data of various resources and scales, limited data on private funding and expenditure [32], etc. The UIS report on the results of its "2020 Survey on Expenditure on Cultural and Natural Heritage" illustrated the problem, as only 62 countries responded; of them, 29 provided sufficient data for the calculation of the index, but eventually only 6 could provide the additional disaggregated data on public and private expenditure [32].

In brief, the SDGs and their specific targets have established $\mathrm{CH}$ as an essential sustainability factor. The quantification, however, of $\mathrm{CH}^{\prime}$ s impact and contribution to the built environment and society, through the SDGs' indicators, remains an extremely complicated task due to the lack of sufficient data and methodologies that can be implemented by at least a group of countries. However, the guiding principles for $\mathrm{CH}$ indicators provided by UNESCO in 2019 [30] can facilitate capacity building and increase domain knowledge on $\mathrm{CH}$ reporting at a local and national level, even at a smaller level of detail than the indicators themselves transcribe.

The objective of the research presented in the following paragraphs was to create a spatially enabled web application for $\mathrm{CH}$ mapping and monitoring at an urban level, in a dashboard format. The case study will be the city of Thessaloniki in Northern Greece, which has a long and-perhaps more importantly —an uninterrupted presence as a major historic city of more than 2300 years, and currently hosts more than 1200 listed sites.

The goal is three-fold: firstly, to identify and map in 2D the $\mathrm{CH}$ sites that are located within the city's administrative boundaries by combining the necessary data that has so far been registered in independent governmental databases. The geographic data will be enriched by a descriptive database containing information about the current state and attributes of each site as recorded in the national cadastral database (e.g., Land/Building Use, Number of Floors, Ownership Status, etc.). It has been noticed that, in most cases, especially regarding architectural heritage sites, there seems to be adequate documentation about the building's former history but very limited resources on its current status and use, which of course are highly dynamic. The information will be organized in a relational database that will be built respecting the existing database templates of the Archaeological and National Cadastre of Greece to facilitate data integration. The archaeological cadastre geospatial database has been constructed based on ISO 19,152:2012 (Geographic Information-Land Administration Domain Model), OGC standards, CIDOC CRM, and the Greek National Framework for Electronic Governance (eGIF). The National Cadastre Database does not directly follow any of the above standards and has its own technical specifications regarding spatial and descriptive data. The collected information will be presented in the form of a spatially enabled dashboard, which is a visually powerful way of presenting data to a heterogeneous audience in a fast and self-explanatory way and at the same time provide useful insights on data correlation and causality through consecutive data filtering [34]. In that regard, the goal of the present research is not to propose a new data model for $\mathrm{CH}$ registration, as several are already in place, but to illustrate a methodology with which already existing data can be aggregated into valuable statistical indicators to provide insights on the $\mathrm{CH}$ stock of each city. The accurate and updated mapping of the city's CH assets can consequently be used to forge a system of spatial and multi-dimensional indicators [35-38] that can facilitate heritage-related urban regeneration projects and also bind $\mathrm{CH}$ to the remaining urban processes and activities (e.g., tourism, environment, real estate, etc.) in the framework of the historic urban landscape, as defined by UNESCO [39].

Secondly, the web app aims at providing additional information of a more technical nature to engineers and public officers, including the total built area in sqm of the $\mathrm{CH}$ site, building permits issued for the site and description of performed renovation works, building regulations such as plot ratio, minimum required area for building, total parcel area and perimeter, etc. This information could be also used by property owners, as well as investors who need a more detailed view of the $\mathrm{CH}$ site. 
Finally, based on the data that has been collected and processed, an effort is made to calculate an estimation, per $\mathrm{CH}$ site parcel, of the funding that needs to be allocated for the protection of $\mathrm{CH}$ in the city, solely in terms of the necessary designs, studies and technical evaluations that need to be carried out and not potential construction costs in terms of building materials, etc. This sum as a total can be used by the local authorities as an initial benchmark that can later be adjusted and fine-tuned based on the actual information on costs for restoration works. Furthermore, if the local authorities decide to start registering in their own right the total funding spent for preservation and restoration purposes at each $\mathrm{CH}$ site, not only will they manage to create an eventual time-series dataset that can lead to weighted sums and averages, but they will also be able to flag out sites for which no funding seems to be allocated at a regular interval.

The hypothesis tested in the case study is that although the city of Thessaloniki, and Greece in general, have presented very limited mapping and reporting capacity on $\mathrm{CH}$, despite it being the main contributor to the national GDP, recent advances such as the gradual completion of the National and Archaeological Cadastral Systems, as well as the country's overall digital transformation, has provided sufficient data resources that can facilitate the development of $\mathrm{CH}$ monitoring applications.

\section{Materials and Methods}

\subsection{Identifying Key Central and Local Agencies Involved in CH Management}

The first step of the methodology included the identification of the central and local government agencies that are involved in $\mathrm{CH}$ management, as well as the various individual stakeholders such as professionals (e.g., architects, archaeologists, structural engineers, etc.) or private interests (e.g., property owners, investors, etc.). The goal was to identify potential data resources but also document potential end-user data needs.

According to the Greek Legislation, four main ministerial agencies can propose and ratify the listing of an architectural building and monument, namely the Ministry of Culture (YPPO), the Ministry of the Environment and Energy (YPEN), the Ministry of Interior-Sector of Macedonia and Thrace (YPES) and the Ministry of Maritime Affairs and Insular Policy (YNANP, regards listings in the insular part of the country). Each of these agencies maintains an independent registry, which can be accessed online, with some basic information about each $\mathrm{CH}$ site such as its administrative location and address (where applicable), name, protection status, listing act and Government Gazette issue in which the act was published, as well as its ownership status at the time of the listing. These registries are only updated when a listing is added or removed by a Ministerial Act, so if a listing has been demolished due to its poor structural condition no such record will exist in the data. No spatial information is recorded in the existing registries and often the listing act itself does not include a map specifying the location of the monument. The lack of coordinates and geographic information has been partly resolved, as of June 2021, with the deployment of a GIS portal by the Ministry of Culture (https: / / www.arxaiologikoktimatologio.gov.gr / (accessed on 5 September 2021), where the location of each monument can be seen in the form of point geometry with its accompanying basic listing information showing in pop-up windows. However, the specific web app regards only the $\mathrm{CH}$ sites that have been listed by the Ministry of Culture, so the problem of geolocating the remaining sites under a common infrastructure remains strong. Furthermore, the information presented in the portal is static and refers to the listing date instead of the monument's current status. A potential connection between the geodata presented in the GIS Portal and the spatial and descriptive cadastral database could contribute to the data collection process, as will be presented below, but is not yet under consideration by the central administration.

Besides the aforementioned government agencies (including their local bureaus and ephorates in each city), there are a variety of other stakeholders that play an active role in the broader field of $\mathrm{CH}$ protection and monitoring in Greece. The municipal authorities, through their town planning and building permit offices, need to acknowledge each monument's unique characteristics and location and incorporate them as such into land 
use plans, urban regeneration projects, etc. It is also their institutional responsibility to issue warning notices to $\mathrm{CH}$ assets owners if there are clear signs of structural damage that can create life-threatening conditions for the building's occupants or the general population. If the owners do not proceed to restoration works in due time, the municipal authorities can pose a fine and, even in extreme situations, demolish the building after receiving the written consensus of the responsible Ministerial Agency.

Other stakeholders include, on one hand, the property owners themselves. If the $\mathrm{CH}$ asset is owned by the broader public sector (i.e., central or local government), then it has to be managed in service of the public interest as dictated by laws and decrees regarding public property. Most of the publicly-owned assets regard archaeological sites, monuments, and administrative offices, and as such, they are used to fulfill their specific purpose. On the other hand, privately owned $\mathrm{CH}$ assets face significant challenges, such as very high and recurring maintenance costs, strict regulations regarding any intervention in the building itself, accompanied by increased bureaucracy in issuing a building permit, building layouts that do not conform to current standards for residential or office use, etc. Often, architectural listings are left to deteriorate by being partially or entirely abandoned, even if their location, mainly the city center, appears ideal in terms of real estate exploitation. This can lead to public health and safety hazards, as any abandoned building would, but more importantly, it leaves extensive square footage unused while there are, for example, increased housing needs. This problem has been acknowledged by the State, which is trying to provide concrete financial tools and incentives to the owners such as exemption of all listed monuments from property taxation, subsidization for the modification of the building into a hotel unit (Law 3908/2011 on Investment Incentives), etc. It has been noticed, however, that the general public is unaware of the state incentives and, as a result, is strongly opposed to the listing of a building, regarding it as restrictive to its property rights [40].

Finally, professionals with a specialization in $\mathrm{CH}$ assets, such as architects, surveyors, structural engineers, art restorers, etc., should be identified as the fourth important stakeholder, since they can provide technical solutions that could trigger the adaptive re-use of heritage buildings and of course prolong the life of each asset in the spectrum of a more circular economy [41,42].

In terms of end-user needs, it is assumed that central and local government agencies need aggregated statistic indices as their interest is not focused on a specific monument but $\mathrm{CH}$ as a system of assets. Professionals and private interests need access to specific information regarding individual monuments that they are interested in. Such data may include information on the listing act and the restrictions that it imposes, issued building permits on the building, current building regulations, etc.

\subsection{Data Collection and Pre-Processing}

Data collection was preceded by a rough conceptualization of the metrics, statistics, and descriptive information that should be reported by the prototype web application in terms of potential end-users needs (either technical or non-technical) and of necessary data for the calculation of Indicator 11.4.1 of the SDGs, namely the building's square footage, land-use, and already conducted restoration works. The data structure and format are presented in Figure 1 as a relational database schema. 


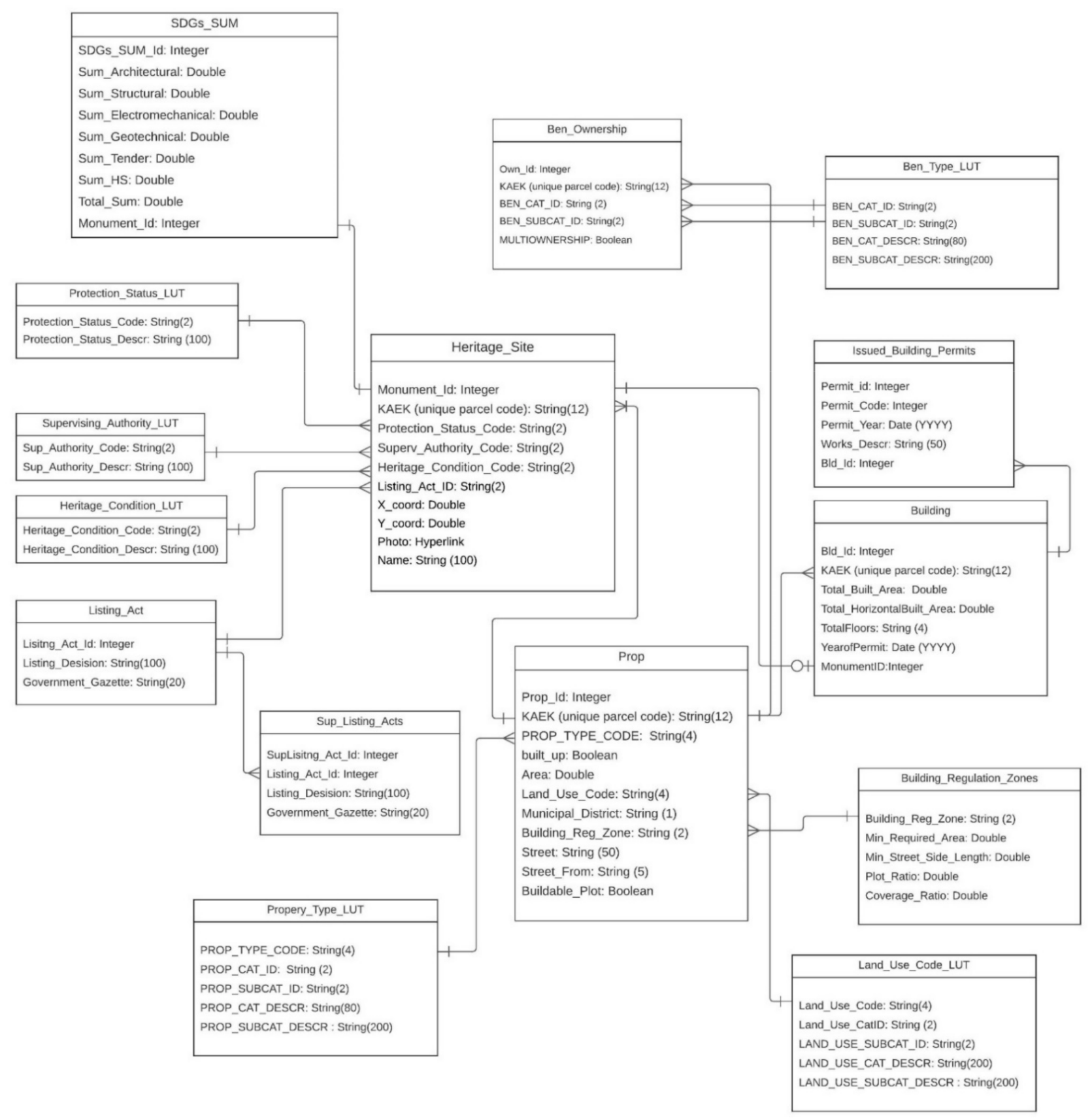

Figure 1. Relational Database Schema for the application.

The table "Heritage_Site" will provide the main information on all CH listings as recorded in the existing ministerial registries. The table contains a unique monument ID for each asset (autonumber), its official name-if any-as recorded in the listing act (e.g., "Villa Allatini"), Protection Status Code, Supervising Authority Code, Current Condition Code, Listing Act ID, a hyperlink to a recent photograph of the asset (to be captured during field verification), its point coordinates in the Greek Grid (EPSG:2100), and the unique parcel code of each site (KAEK) to be retrieved from the cadastral database and used as a foreign key. Coded fields are connected through a many-to-one relationship with look-up tables (LUT) providing the text description of each code; e.g., in the case of the Supervising Authority Code, value 01 corresponds to the Ministry of Interior, value 02 to the Ministry of Culture, value 03 to the Ministry of the Environment and Energy, and value 04 to the Ministry of Maritime Affairs and Insular Policy. The Protection Status 
Code and its accompanying LUT have emerged from the national legislative framework on heritage which defines several protection categories such as Entire Building/Part of (value 01), Building Envelope/Façade (value 02), Historic/Archaeological Site (value 03), etc. The Heritage Condition Code field and accompanying LUT contain four values, defined by the current research, namely Good (refers to regularly restored buildings), Adequate (refers to buildings that have been restored in the past but need additional works at present due to evident material degradation), Bad/Ruin (refers to abandoned buildings that face severe structural damage), and a null value that will be appointed to archaeological sites (byzantine temples, etc.) whose condition cannot be easily evaluated in the field. These values will be assigned to each $\mathrm{CH}$ asset during the field verification and documentation process. Finally, the Listing Act ID is connected through a many-to-one relationship to the Listing Act table which contains information on the listing act protocol number and the Government Gazette issue in which it was published. Since each Listing Act might have been partially modified by following ministerial acts, an additional table is created in the database, entitled Supplementary Listing Acts, which is connected through a many-to-one relationship to the Listing Act table providing the necessary information on these acts (i.e., protocol number and Government Gazette of publication).

To populate the Heritage Site table, a desktop GIS project was created, having satellite imagery as a basemap and the cadastral parcels spatial feature class (which can be downloaded from the geoportal of the "Hellenic Cadastre Agency" at https: //www.ktimanet.gr/geoportal/catalog/main/ (accessed on 20 August 2021)) as an auxiliary layer for the geolocalization of the $\mathrm{CH}$ assets. Each parcel has already been assigned by the Cadastral Agency a unique 12-digit parcel code (KAEK), where the first two digits indicate the administrative prefecture of the country in which the parcel spatially belongs, the other three digits indicate the municipality (although these three digits refer to a former administrative municipal structure of the country that is no longer valid), the next two digits the cadastral sector, the next two digits the cadastral unit and the final three digits the number of the parcel inside the specific cadastral unit. The parcels feature class was filtered through its five first digits to include only those whose unique code refers to the city of Thessaloniki.

An extensive search was conducted manually in all three $\mathrm{CH}$ assets registries that are maintained by the Central Government (i.e., Ministry of Culture, Ministry of the Environment, and Ministry of Interior), using their web user interface, through applying attribute filters regarding the administrative region (municipal boundaries) in which each monument lies. The information was digitized as point geometry following a simple GML schema (Figure 2) using the Heritage Site table's structure. The listing acts' data was also recorded in the corresponding tables of the database.

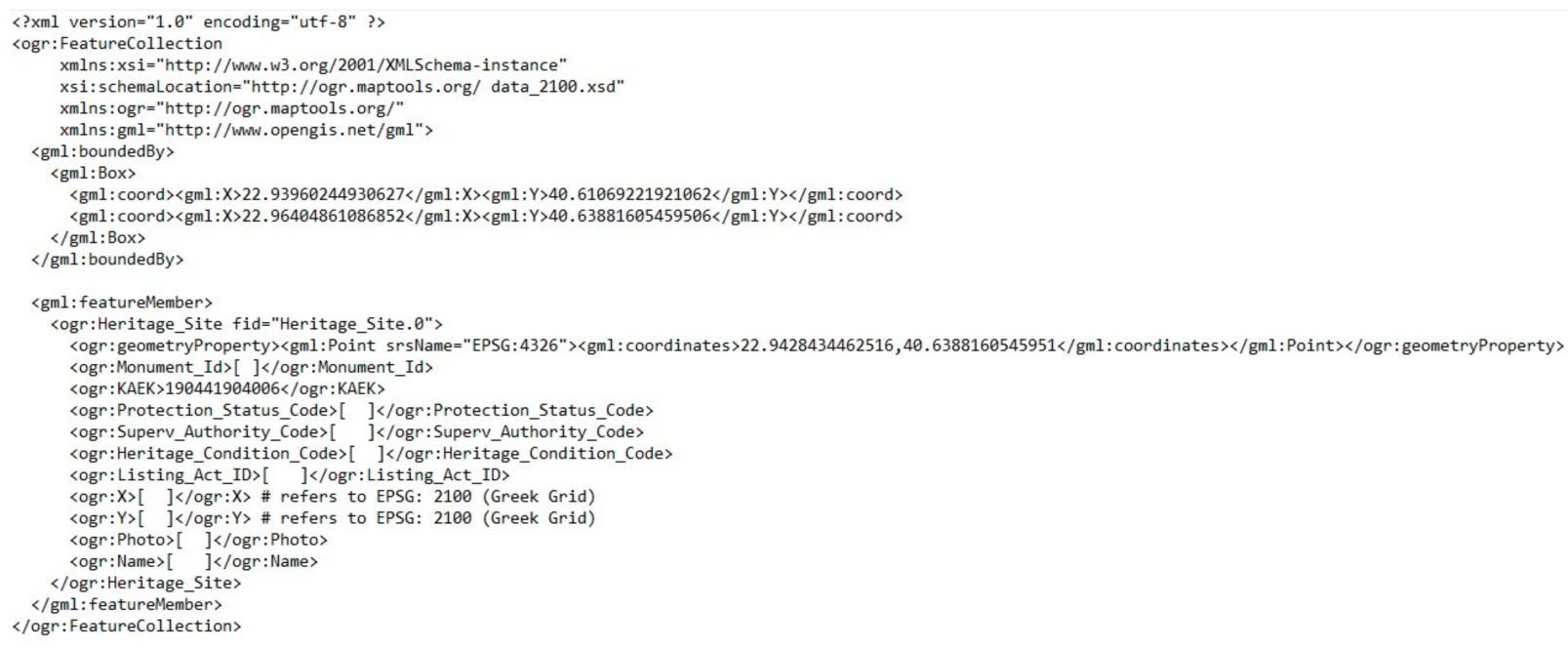

Figure 2. GML schema used for cultural heritage $(\mathrm{CH})$ assets point digitization and recording. 
Google Earth (GE) and Street View were used to verify the location of each asset according to the registries' description. Even at this early stage of the research, it became evident that quite a few of the listed architectural monuments might have been demolished as they did not appear in either GE or Street View (Figure 3) or, in some cases, although they appeared in the Street View images (of 2011), they did not appear in Google Earth's more recent satellite imagery (of 2017) (Figure 4). In both cases, these records were flagged for further field inspection.

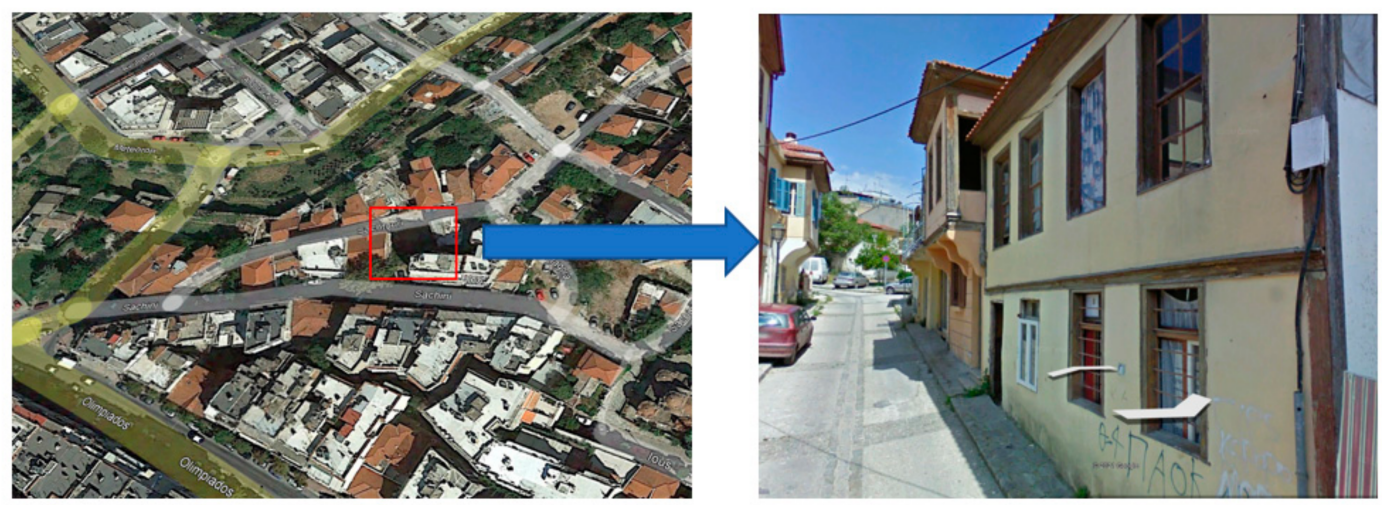

Figure 3. Two listed buildings in Sachini Street (Ano Poli Area) that were possibly demolished between 2011 and 2017 since they appear in Google's Street View but not in Google Earth.
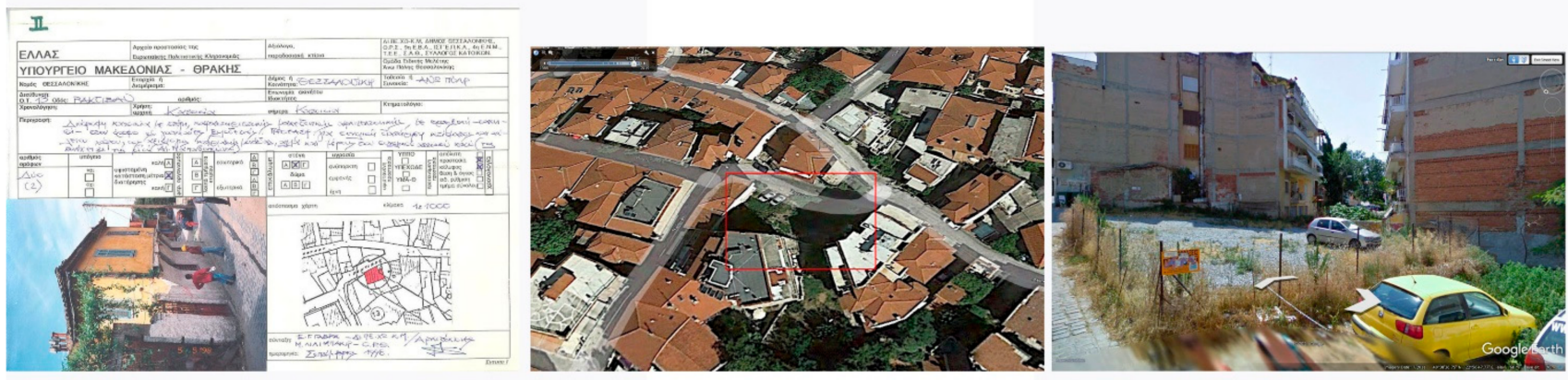

Figure 4. Listed building in Raktivan Street (Ano Poli Area) that appears to be demolished between 1998 (date of the inventory record of the Ministry of Interior-Sector of Macedonia and Thrace) and 2011 (date of Street View imagery).

Once the location of the monuments was finalized, the outline of the listed buildings was also manually digitized in a separate feature class. A spatial join function connected the $\mathrm{CH}$ assets to their corresponding cadastral parcels and provided their unique parcel code (KAEK). Through the parcel code, manual research was conducted in the descriptive cadastral database to collect and register additional summarized information about the assets. The structure of the cadastral relational database, as described in the technical documentation and specifications provided by the "Hellenic Cadastre Agency", was followed to a significant extent. More specifically, the "Prop" table (Figure 1) provides general information on each parcel such as a unique record code (Prop_ID: autonumber), the unique parcel code (KAEK), the property type code, the area of the parcel (in square meters), land-use code and its current address (street name and number). This data was directly copied from the cadastral database. Additional information corresponding to each parcel's Municipal District and Building Regulation Zone will be produced through spatial join operations in the desktop GIS application. Finally, information will be stored in the specific table regarding whether the parcel already contains a building structure or/and whether it can be built according to the existing regulations (both in Boolean format). The "Prop" table is connected through a many-to-one relationship to the "Property_Type", 
"Land_Use_Code" look-up tables that are copied from the cadastral database and contain the description of each assigned code per category. The "Building" table contains derived summarized information from the corresponding "BLD" table of the cadastral database, such as the total built and the horizontal plan area of the existing $\mathrm{CH}$ building in square meters, the number of the total floors, and the year of the issued building permit. This table is connected through a many-to-one relationship to the "Prop" table (using the unique parcel code as a foreign key), through a one-to-one relationship to the "Heritage_Site" table (using the Monument_ID as a foreign key), and through a one-to-many relationship with the "Issued_Build_Permits" table. The latter table provides information (permit protocol number, year of issue, description of performed restoration works) on all issued building permits after 1978 regarding $\mathrm{CH}$ assets. This information was extracted through manual research, based on the corresponding address and the use of keywords (e.g., "listed site", "restoration works", etc.) from the publicly available municipal building permit registry (https:/ / opengov.thessaloniki.gr/e-ypiresies/anazitiseis/poleodomikes-adeies (accessed on 25 May 2021). The year 1978 is considered a landmark year for Thessaloniki, as a major 6.5 magnitude earthquake (level VIII (8) in the Mercalli Intensity scale), left 49 people dead and more than 200 injured, causing substantial structural damage to heritage and ordinary buildings that in some cases is still evident. In that regard, the issued building permits with the description of the works that were undertaken can provide some background information on the maintenance or restoration level that each listed building has received since the earthquake.

Table "Ben_Ownership", contains information on the property owners' category and subcategory (e.g., private interests, Greek State property, local government property, etc.) and whether there is a multi-ownership status (in a Boolean form) in each parcel. This information was extracted manually from the cadastral database and is connected through a many-to-one relationship to the corresponding "Ben_Type" LUT. This particular LUT was copied from the cadastral database, but was eventually simplified so that all property owners' categories which essentially refer to private interests (e.g., private individuals, companies, investment agencies, financial institutions, etc.) were reduced to a single record, entitled "Private Interests". The "Ben_Ownership" table is also connected through a many-to-one relationship to the "Prop" table using the unique parcel code (KAEK) as a foreign key.

All the information collected is by default sensitive to possible registration errors in the cadastral database. It is worth noting that the $\mathrm{CH}$ listings are not marked as such in any field of the specific database, something that could facilitate the process of data collection even further. A set of basic control checks was performed in the collected data; for example, the identification of $\mathrm{CH}$ assets that have a recorded initial building permit year that is more recent than their actual listing year. In some cases, the restoration project's permit was recorded in the cadastral database (extracted from the property's contract) instead of the initial permit (Figure 5a), whilst in other cases, the protection status of the building regarded only its envelope/facade (Figure $5 b$ ) or there was even an extension of the building with the addition of several floors (Figure 5c).

The final set of information was extracted from the Municipal Spatial Data Infrastructure (http:/ / gis.thessaloniki.gr/sdi (accessed on 10 May 2021) and regarded the polygons of the municipal districts (Thessaloniki is divided into six districts) and the current building regulations that apply to each parcel (minimum area, plot ratio, coverage ratio, etc.). This information was connected to the parcels and the $\mathrm{CH}$ assets through a performed spatial join. The municipal district of each parcel was recorded as such in the "Prop" table. The Building Regulation Zone Code was also recorded in the "Prop" table and connected through a many-to-one relationship to a corresponding table that provides detailed information on the specific building regulations of each zone (i.e., minimum required area, minimum parcel street-side length, plot ratio, and coverage ratio). Through automated spatial processes, a gross check was performed on whether each parcel complied with 
the existing building regulations. This information was stored in a Boolean format at the

"Prop" table (field: Buildable_Plot).

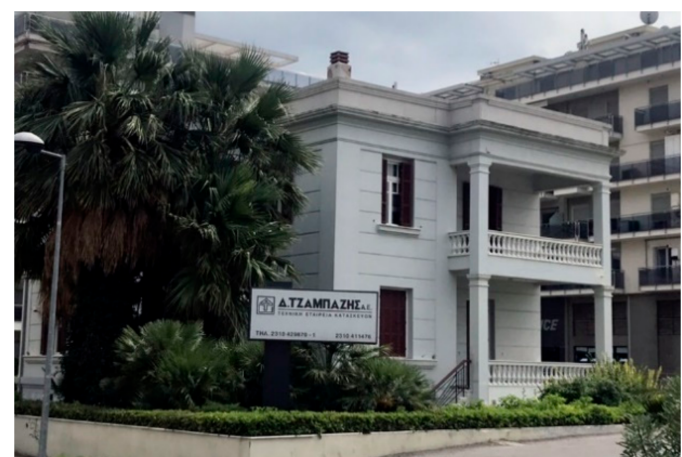

(a)

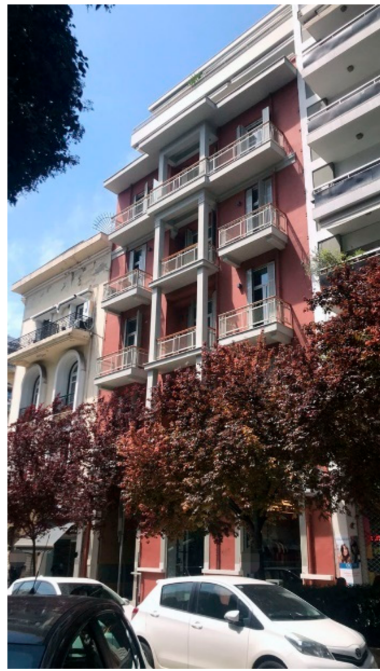

(b)

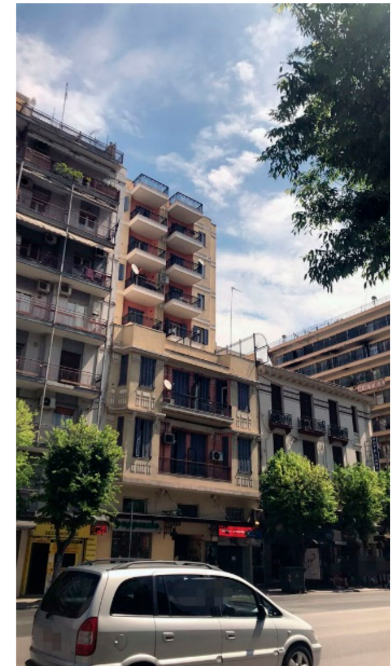

(c)

Figure 5. Examples of cases where the recorded building is more contemporary than the actual building: (a) restored building at Logothetou Str.; (b) façade restoration and rebuilding at P.P. Germanou Str.; (c) building extension at Egnatia Str.

\subsection{Field Verification and Documentation}

Once the initial list of $\mathrm{CH}$ assets was drafted (roughly 1300 records), a kml (Keyhole Markup Language) file was extracted and loaded into an iOS GPS Camera app (GPS Camera 55, Version 2.4), so that geotagged photos of each listed building/landscape could be taken in situ and added in the database presented in Figure 1 (Field: Photo of the "Heritage Site" table). The photographic documentation of $\mathrm{CH}$ buildings is considered crucial as it can immediately provide visual information on each asset to a significant audience, either local or global. This can of course be easily achieved for widely known monuments through the web, but it is far more difficult for individual listings. In a few cases, access was not allowed in the properties, especially in abandoned mansions or former industrial complexes, so an image of these assets was not eventually captured. The field visit verified that approximately 30 listings had been demolished (or collapsed), almost all of them located in Ano Poli, which is the upper part of the city (Municipal District C) (view example in Figure 6).

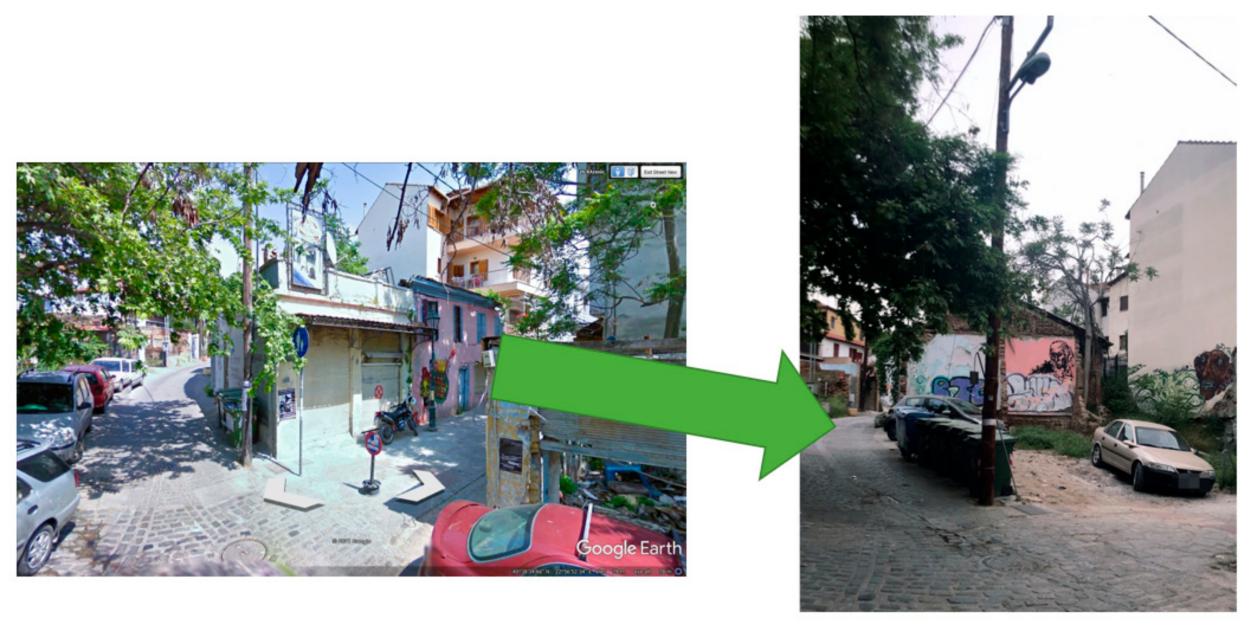

Figure 6. Field verification of demolished listed buildings in the area of Tsinari in Ano Poli. 
During each field visit, an additional attribute was recorded for each $\mathrm{CH}$ asset regarding its current condition (April-June 2021), namely Good, Adequate, Ruin/Bad (Field: Heritage Condition Code of the "Heritage Site" table). Archaeological sites, Byzantine and Ottoman monuments were excluded from this condition categorization as their structural and architectural complexity does not allow for any such quick visual assessment. As a result, the Heritage Condition Code for these specific listings was left null in the database. Examples of each category can be shown in Figure 7.

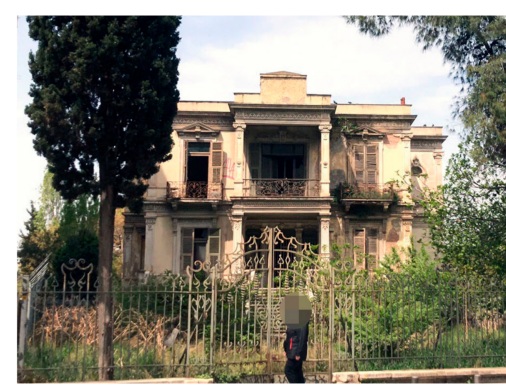

(a)

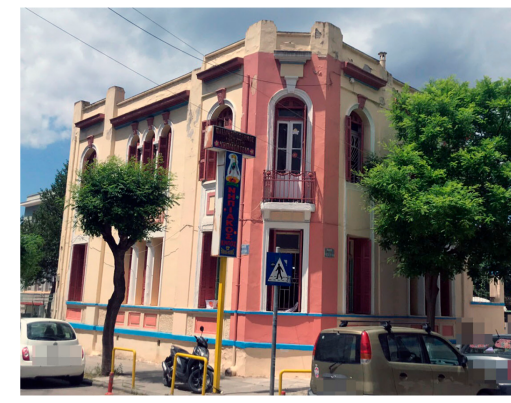

(b)

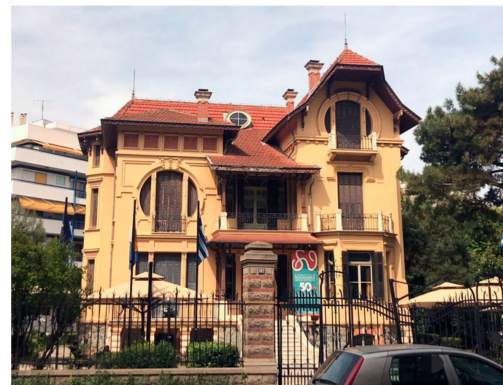

(c)

Figure 7. Examples of current condition categorization; (a) Bad/Ruin (abandoned building); (b) Adequate (occupied with obvious maintenance issues); (c) Good (occupied with apparent regular maintenance).

The recorded $\mathrm{CH}$ asset's condition, combined with whether a building permit was found in the municipal digital registry, will be crucial in calculating Indicator 11.4.1.

\subsection{Calculating Indicator 11.4.1 of the SDGs}

The information that was collected in the previous two steps can be used to calculate Indicator 11.4 .1 of the SDGs, in terms of performing all the necessary architectural, structural, geotechnical, and electromechanical evaluation studies to ensure the resilience of the city's cultural heritage assets to wear and tear damage, as well as potential geohazards such as earthquakes, flooding, etc. The cost that was calculated regards only the studies and drafts and no actual construction and building material costs, since there is no such feedback available at present.

The cost was calculated using the most standardized and widely used regulation in the country which is the "Regulation of Estimated Fees for Studies and the Provision of Technical and other related services" (published in the Government Gazette issue 2519/B/20-07-2017). Technically speaking, the specific regulation is only legally binding for the procurement of studies by the broader public sector (i.e., central and local government agencies). Respective studies for privately owned properties are subject to individual negotiation between the owners/managers and the technical professionals who offer their services and know-how. This regulation provides specific mathematical formulas based on which a proposed budget for each category of study is produced. The main input required by these formulas regards the total built area and total horizontal built area of the heritage site (information that can be retrieved from the "Building" table of the database), as well as its land use (retrieved from the field "Land_Use_Code" of the "Prop" database table). For example, in the case of a structural resistance evaluation study, the formula provided by the state regulation is the following:

$$
\mathrm{A}=\left\{\kappa+\frac{\mu}{\sqrt[3]{\frac{\mathrm{E} *(\mathrm{TAo}) * \Sigma \sigma \tau * \Sigma \mathrm{B} v * 100)}{178,3 * \tau \kappa}}}\right\} * 1.06 * \mathrm{E} * \mathrm{TAo} * \Sigma \beta \nu * \Sigma \sigma \tau * \tau \kappa
$$

where $\kappa$ and $\mu$ are predefined factors based on the construction material and the type of building (in our case $k=3$ and $\mu=37$ ); E refers the total built area of the building in square meters; TAo is a predefined factor set at 9.75; $\Sigma \sigma \tau-\Sigma \mathrm{B} v$ are predefined factors based on the building's land use. $\Sigma \sigma \tau$ values range between 0.24 (hospitals) and 0.7 (water tanks), 
while $\Sigma \beta v$ values range between 0.5 (underground water tanks) and 3.5 (water towers). Finally, $\tau \kappa$ is a factor determined annually by the Greek Ministry of Public Works regarding all public studies ( $\tau$ K is set at 1.199 for 2021).

Several assumptions were undertaken to produce a more realistic calculation of the total cost, in the sense that not every evaluation study (either architectural, structural, etc.) needs to be performed in every listed building as many of them have already been fully restored, structurally reinforced, etc. In broad terms, the calculations include the cost for the structural assessment by experts of all listed buildings to ensure their compliance with the current national anti-seismic regulation. This is paramount for $\mathrm{CH}$ protection and, of course, for the civil protection performance of the city itself. Additional costs for studies such as architectural designs were also calculated in cases where such documentation appears to be missing (no original or subsequent building permit was identified in the municipal registry). Finally, concerning the recorded abandoned buildings (condition status: Bad/Ruin), a full restoration cost was calculated according to its currently registered use in the cadastral database (including electro-mechanical and geotechnical evaluation studies). However, if an existing restoration study was found in the Permit Registry, whether implemented or not, no additional cost was calculated as all the necessary calculations-in terms of static reinforcement and architectural documentation-have already been performed. Each asset's classified condition combined with whether existing technical documentation was to be expected, determined the pace at which each study could proceed in terms of field verification and measuring, varying from $50 \mathrm{sqm} /$ day to $100 \mathrm{sqm} /$ day.

Each category of studies was calculated individually for each $\mathrm{CH}$ asset and can be reported as such. This information was recorded in a separate table in the database entitled "SDGs SUM" which is connected through a one-to-one relationship to the "Heritage Site" table, using the Monument_Id field as a foreign key. The table contains in separate fields the calculated sums for the architectural, structural, electro-mechanical, and geotechnical evaluation studies, the tender documentation and health and safety folders cost (applicable only in the case of publicly owned properties), and a total cost value as an aggregation of all individual values.

\section{Results}

\subsection{Data Collection and Documentation}

Data collection and integration was a rather lengthy process as several individual data registries had to be combined into a common new database. Record overlapping was noticed between the different sources which could be identified only after geolocating each listed item. Furthermore, architectural listings that have been demolished or collapsed were not updated as such in the state registries. In exceptional cases, there were even findings of buildings that were demolished only a few months before their listing act was published in the Government Gazette, e.g., the building at 25-27 Monastiriou Street which is even included in the current Archaeological Cadastre web-app, although it is an apparent contemporary building that does not fit its listing description in any shape or form. That can be partly attributed to the extremely bureaucratic processes of listing a $\mathrm{CH}$ asset, the lack of communication between the various agencies (such as the listing supervising authorities and the municipal building permit office), and the lack of sufficient database updating. In that sense, field verification and documentation were imperative.

Furthermore, the data that was retrieved from the cadastral database between January and June of 2021 is only a snapshot of a constantly updated and thus highly dynamic database. Finally, the Building Permit Registry of the Municipal Authority is quite cumbersome, lacking data and recording former address names and numbers even in more recently issued permits.

\subsection{Building the Web Application}

The web application for the visualization and reporting of the collected data was implemented through Dash by Plotly, which is a powerful open-source Python library, 
ideal for building data analysis apps in fully customized user interfaces [43]. Dash apps are viewed in a web browser and in that respect are cross-platform [43].

The multipage web application can be accessed through the URL https://www. thessheritage.gr/ (accessed on 15 September 2021) and does not require registration. The goal was to create a self-explanatory and user-friendly interface that can be used by anyone who has an interest in viewing the $\mathrm{CH}$ assets of Thessaloniki. Currently, the application is available in both Greek and English and is thus accessible to a wider audience.

The layout of the application is organized as follows: the Home/Introductory page (Figure 8) contains some basic statistic figures and indicators as identified in previous studies, such as the total number of $\mathrm{CH}$ assets in the city, the percentage of properties (parcels) that host a listed building/landscape along with the respective area percentage [44], the number of unique listing acts, the number of UNESCO World Heritage Sites [45] and the number of $\mathrm{CH}$ assets per 10,000 residents [46]. An image carousel provides a visual introduction to some of the city's listings and a word-cloud puzzle adds some important names and locations. Finally, a brief timeline of ten important dates aims at introducing the city's history to the application's visitors.

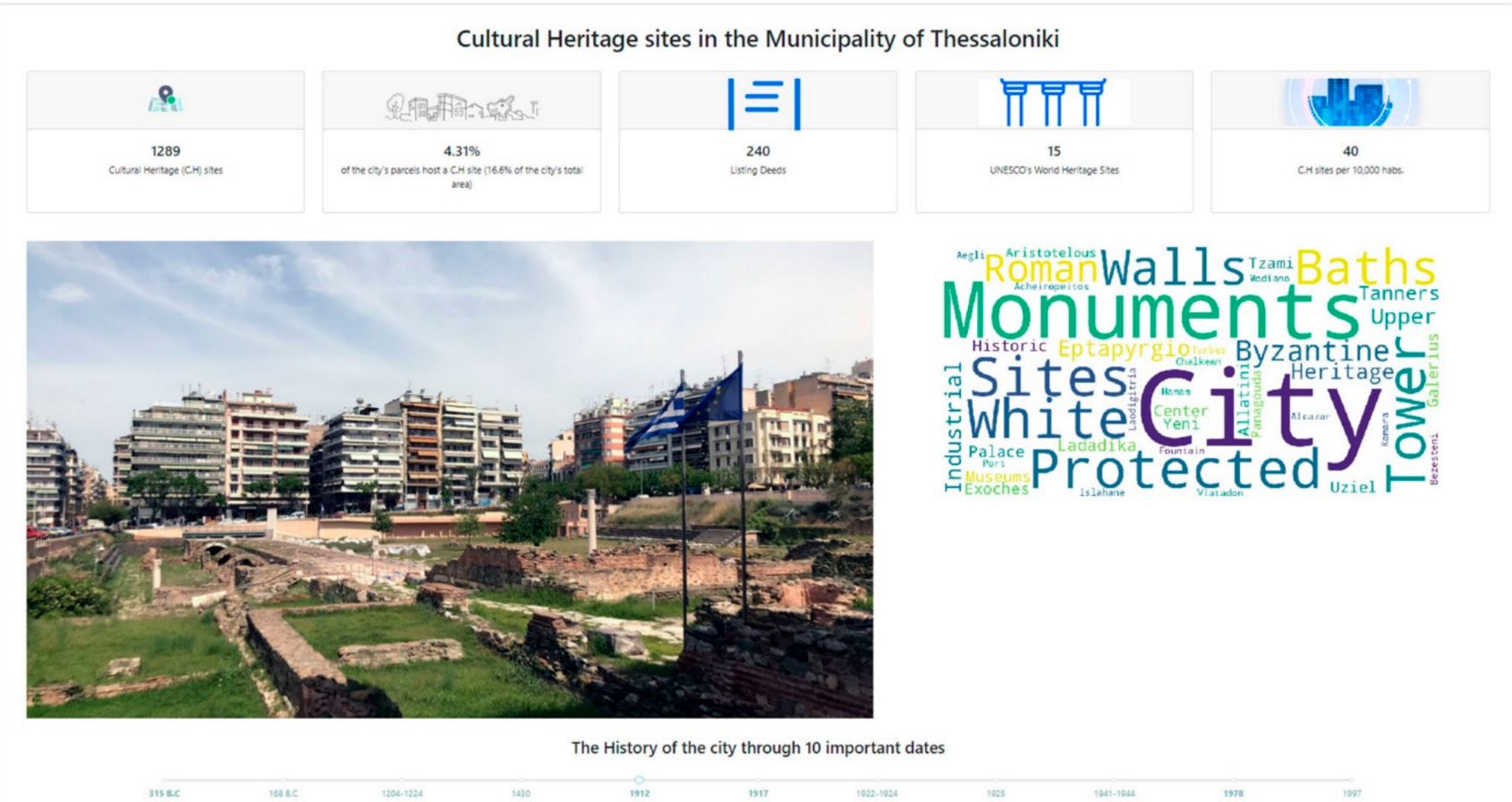

Figure 8. Home/Introductory page of the web app.

The second page, entitled " $\mathrm{CH}$ Assets in Thessaloniki", is essentially a geographically enabled dashboard that provides detailed statistical information, and attribute filtering capabilities about the listed sites. It includes five main elements described as follows (Figure 9): a map of the city (created using Dash Leaflet library), where $\mathrm{CH}$ sites appear initially in clusters, while zooming-in reveals their exact location. A pop-up window provides a set of basic information about each listing. The basemap (Open Street Map is used as the default option) can be altered to several different options, including satellite imagery, topographic maps, etc. Finally, layers such as Parcels, Buildings, Protected Heritage-Nature Zones can be switched on and off according to the user's preference. Measuring capabilities (area, distance) have also been incorporated into the map. The second element regards a pie chart with a drop-down menu where the user can select a specific attribute of the $\mathrm{CH}$ assets to be summarized in the form of percentages. Such attributes include, for example, the municipal district, land use category, and subcategories, 
ownership and protection status, etc. If a specific value of an attribute is selected, a filter is applied to the map providing a spatial representation of the data. The third element is a bar chart depicting the registered construction period of each $\mathrm{CH}$ listing. The bar chart is connected to the map and the pie chart, as well as the following graph that provides information on the listing dates. The connection between the different graphs allows for extensive attribute filtering and demonstrates the effectiveness in visualizing data that a spatially enabled dashboard provides. The next element of the page is a bar chart that depicts the listing year (in terms of deed publication in the government gazette) for each monument. This graph is directly connected to the previous three elements, to provide increased filtering capabilities. Finally, two sidebar charts provide information on the streets that have the highest and lowest number of $\mathrm{CH}$ assets, as a percentage of the total parcels located in them. A minimum threshold value of 10 overall properties per street was used to exclude particularly small-sized streets located in the city center. These graphs can be insightful on specific locations that seem to provide a very accurate snapshot of the city's architectural heritage and, on the other hand, provide information on more isolated sites that are surrounded by modern constructions. These two sidebars are connected only to the map. All graphs can be downloaded in a png image format to be used for further individual research.

The third page, entitled "Listings' Information", provides more detailed information on each $\mathrm{CH}$ asset in a tabular form (Figure 10). An initial multi-page data table serves as a search index where the user can locate a listing based on its unique parcel code, name, address, protection status, etc. (parcel codes can be easily retrieved from the pop-up map windows of the previous page). Once a specific listing has been selected, four new elements appear on the screen. Firstly, a table presents additional detailed information on the listing (e.g., its land use, property type, building year, listing deeds, building regulations, supervising authority, etc.), followed by a map showing the listing's exact location with a variety of possible basemaps. Finally, a recent image of the listing is presented, acquired during the field verification process (April-June 2021), followed by a pdf file of the Listing Act as published in the Government Gazette (in Greek) that can provide additional insight on the $\mathrm{CH}$ asset's history and special protection terms and conditions. It should be noted that this page could easily incorporate additional technical data, such as building permit designs or even 3D representations of monuments in the form of 3D mesh objects, but due to copyright and GDPR restrictions this was not allowed in the current application.

The fourth page, entitled "Indicator 11.4.1 of the SDGs", provides all the necessary introductory framework regarding SDG 11, Indicator 11.4.1, and reports back on the calculations that were performed as an integral part of the current research. The page contains four main elements. Firstly, a set of three cards with basic information on the SDGs, Goal 11 and Indicator 11.4.1. Hyperlinks to official web pages are added to each card for more information if requested by the user. A map, then, presents the listed assets in a thematic symbology according to the total sum for evaluation and conservation studies calculated for each one. A pop-up window provides additional information on each asset. The third element of the page is a sunburst diagram accompanied by four drop-down menus that enable summarized visualization of data in a hierarchical format according to their protection status, condition, or ownership type. The final so-called "leaf" regards the sum of the calculated preservation cost for each listing as a total or per individual type of study. Finally, a list of the critical assumptions made for the calculation of the indicator 11.4.1 is presented in the form of a card. These assumptions are of course subject to further debate and scrutiny. 


\section{Cultural Heritage (C.H) Sites in the Municipality of Thessaloniki}

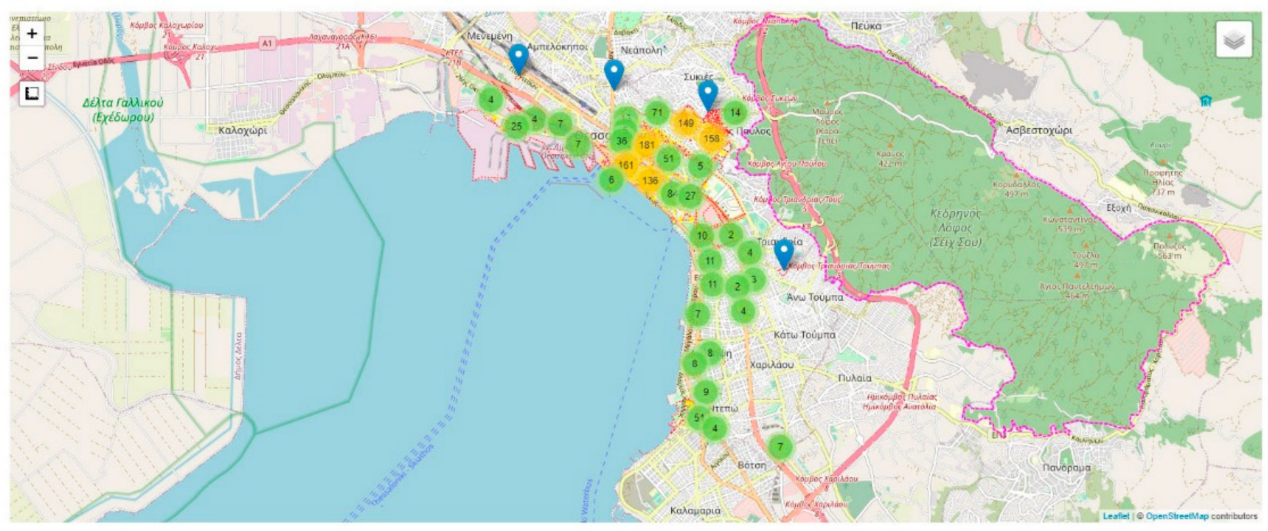

Choose a variable
Municipal District
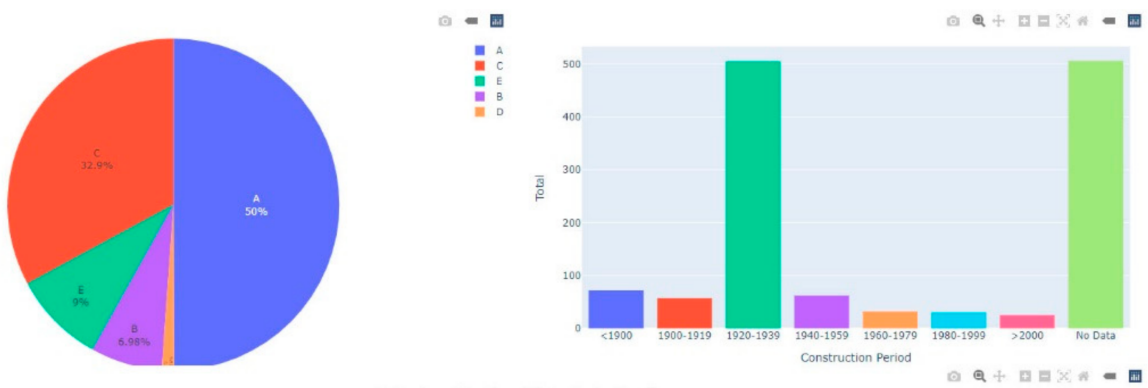

Listing's publication date in Govt. Gazette
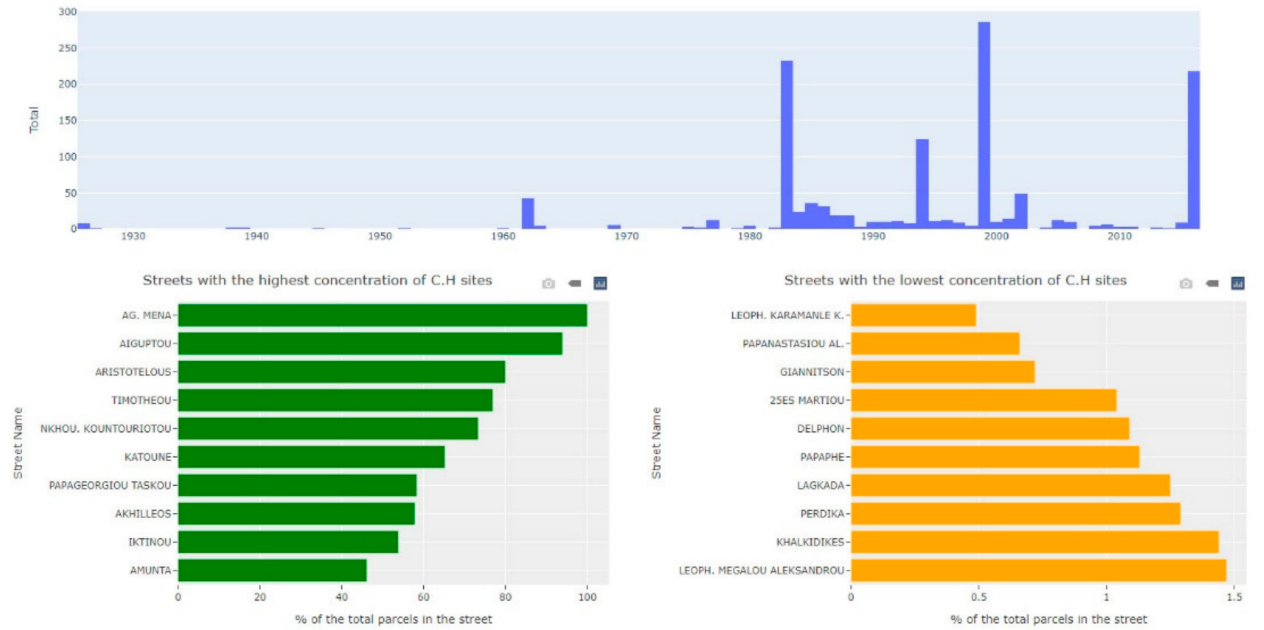

Figure 9. Layout of the "CH Assets in Thessaloniki" page of the web application. 


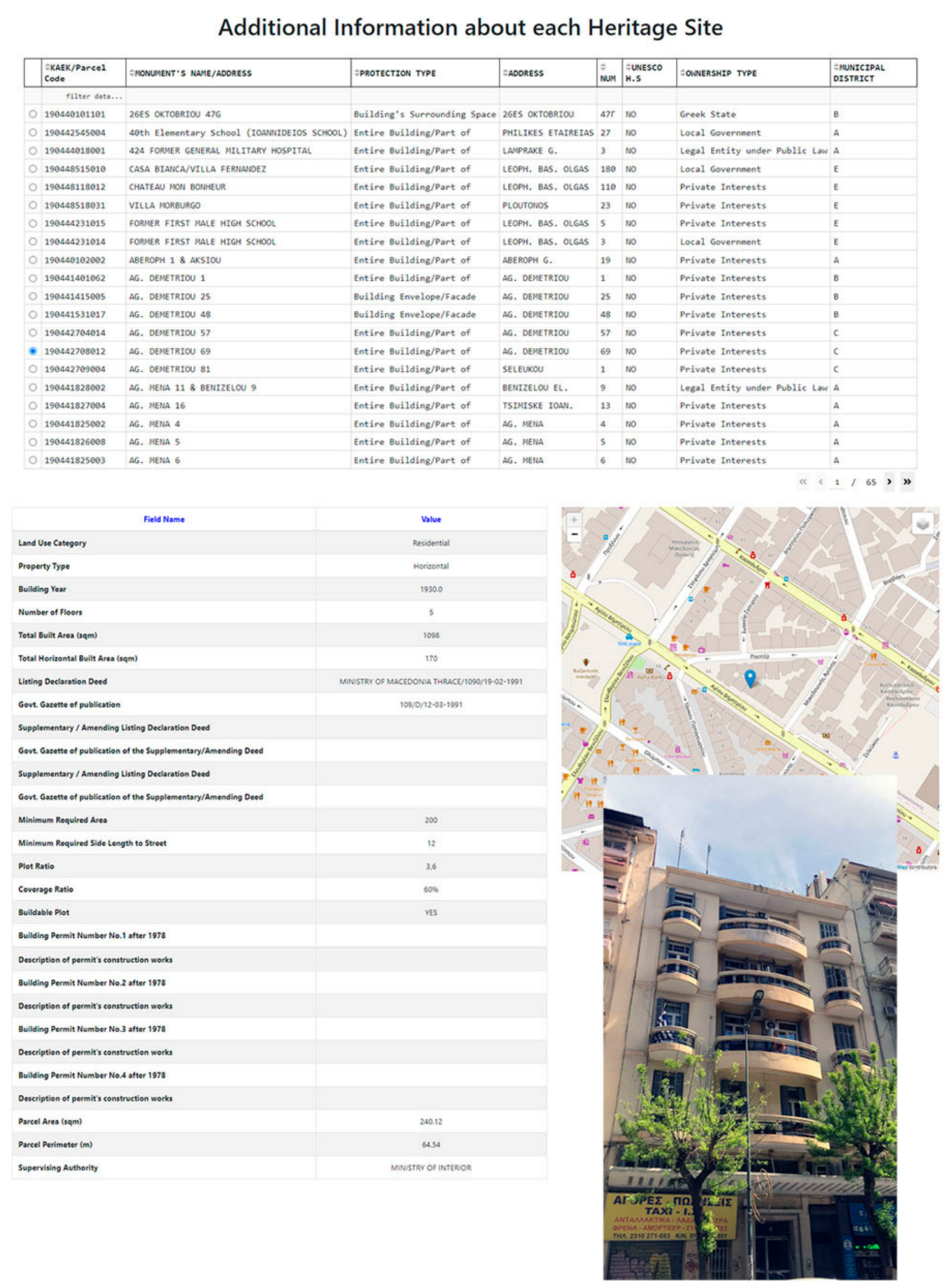

Figure 10. Layout of the "Listing's Information" page of the web application.

The fifth page, entitled "Legislation", provides all the necessary National and International Legal Framework (Soft Law) regarding the protection and conservation of $\mathrm{CH}$ in the form of two distinct menus. National legislation can be viewed in a pdf format as published in the Government Gazette (in Greek).

The final page is a simple contact form for any feedback or suggestion that a visitor would like to contribute.

The web application was deployed through the Python Anywhere platform with approximately 1.8 GB size of server space needed.

\subsection{Data Visualisation and Reporting}

A total of 1289 listed $\mathrm{CH}$ assets were identified inside Thessaloniki's administrative boundaries, located in approximately $4.3 \%$ of the city's parcels. Fifty-three parcels host more than one listed monument. Fifteen UNESCO World Heritage Sites can be found in the city (such as the White Tower, the City Walls, Rotonda, Eptapyrgion, and others). Approximately $80 \%$ of the listed monuments are in the Municipal Districts A and C, being the historic city center and the Upper City (Ano Poli) (Figure 11). The remaining Municipal Districts host very distinct listed assets such as former industrial spaces, dating back to the beginning of the 20th century (Districts B and C), or former mansions and villas (District E) (Figure 11). 


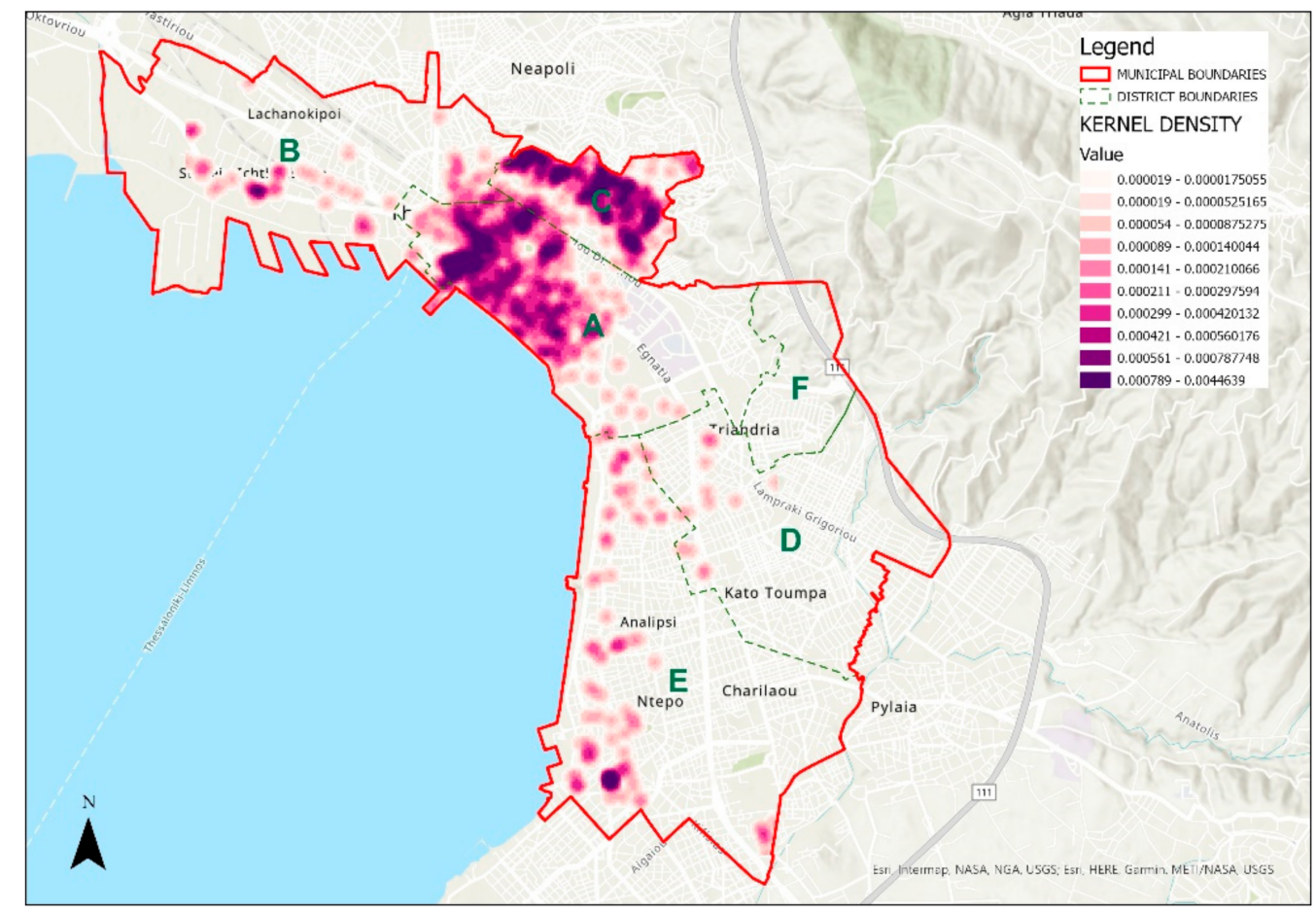

Figure 11. $\mathrm{CH}$ assets distribution per Municipal District (Kernel Density).

More than $50 \%$ of the $\mathrm{CH}$ assets are of a current residential use, while commercial, services, and cultural uses follow at about $10 \%$ each. Moreover, $82 \%$ of them are privately owned, while $8.53 \%$ are State-owned and $3.72 \%$ are owned by the Municipality of Thessaloniki. Of the listings' protection status, $66.5 \%$ regards a part of or the entire building, while more unique cases such as protected Ottoman fountains can also be found at a much lower percentage. Considering that $56 \%$ of the monuments were listed by the Ministry of Interior (Sector of Macedonia and Thrace), it is evident that the recently launched Archaeological Cadastre web app (which as was previously mentioned hosts only the monuments that were listed by the Ministry of Culture), cannot provide sufficient information on Thessaloniki's cultural heritage stock.

More than 500 (39\%) of the listed monuments date back to the period between 1920 and 1939, while another 506 do not have a registered building date. It can be assumed that the latter case refers to buildings constructed before the great fire of 1917 that ravaged the historic city center and for those reasons no such record can be retrieved.

Three major peaks can be identified in the listing date chart, namely 1983, when 233 assets were listed mainly in the historic city center; 1999, with the listing of 287 assets mainly in the upper city; and more recently, in 2016, with the addition of 218 listings in the historic city center.

With regards to the maintenance level that the $\mathrm{CH}$ assets have received, 562 entries (approximately $44 \%$ ) had issued a building permit for a variety of maintenance works since 1978. Of them, 130 (approximately 10\%) had a full restoration study undertaken, although in some cases the field inspection showed that these studies were not eventually implemented.

Finally, as it concerns the $\mathrm{CH}$ assets' condition, $65 \%$ is in a good or adequate condition, while $26 \%$ (335 assets) appear to be in bad condition. The geographical distribution of each category does not reveal a specific pattern, although it could be noted that, generally, $\mathrm{CH}$ assets located in more commercial streets (and thus having a higher market value) present a better maintenance level. The $\mathrm{CH}$ assets that appear to be in a bad condition sum up to a total built area of 221,000 sqm which, if restored, could be adaptively reused for housing, cultural, administrative purposes, etc., rather than being left to rapidly deteriorate. 


\subsection{Reporting on Indicator 11.4.1}

The collected data from the various official sources enabled a rough estimation of the total cost of studies that would access the condition of $\mathrm{CH}$ assets (monuments excluded). Key data include the total square footage of the buildings, land use, and ownership type (as described or calculated from the descriptive cadastral database), their current condition, and whether a building permit was recorded in the municipal registry since 1978.

A total of 70.2 million euros was calculated for all the necessary studies. Of this, $74 \%$ (about 52.2 million euros) regards $\mathrm{CH}$ assets that belong to private interests, while 13\% (about 9.2 million euros) regards assets that belong to the State. As expected, 38.9 million of the total sum regards the necessary studies on assessing the current structural performance of the listed buildings, which was considered a prerequisite for any true effort towards urban heritage protection. The four $\mathrm{CH}$ assets that are expected to present the higher study costs, based on the collected data and assumptions, are presented in Table 1.

Table 1. $\mathrm{CH}$ assets presenting the highest estimated study cost.

\begin{tabular}{ccc}
\hline Name & Municipal District & Total Cost (Euros) \\
\hline Former Industrial Complex YFANET & $\mathrm{D}$ & 4.1 million \\
Former Customs Building (Port) & $\mathrm{A}$ & 2.6 million \\
Former Industrial Complex of Allatini Mills & $\mathrm{E}$ & 2.3 million \\
Former Industrial Complex of Allatini Ceramics & $\mathrm{E}$ & 1.8 million \\
\hline
\end{tabular}

The sunburst diagram of the web application can provide efficient visualization of the cost distribution in terms of ownership type, protection status, and site condition.

It is important to note for the sake of completeness, since archaeological sites and monuments (Classical, Byzantine, and Ottoman) were excluded for reasons of simplicity, that in the period between 2000 and 2020 these sites received EU funding of approximately 18.6 million euros for various restoration and regeneration works (Figure 12 presents the location and a categorical representation of the received funding).

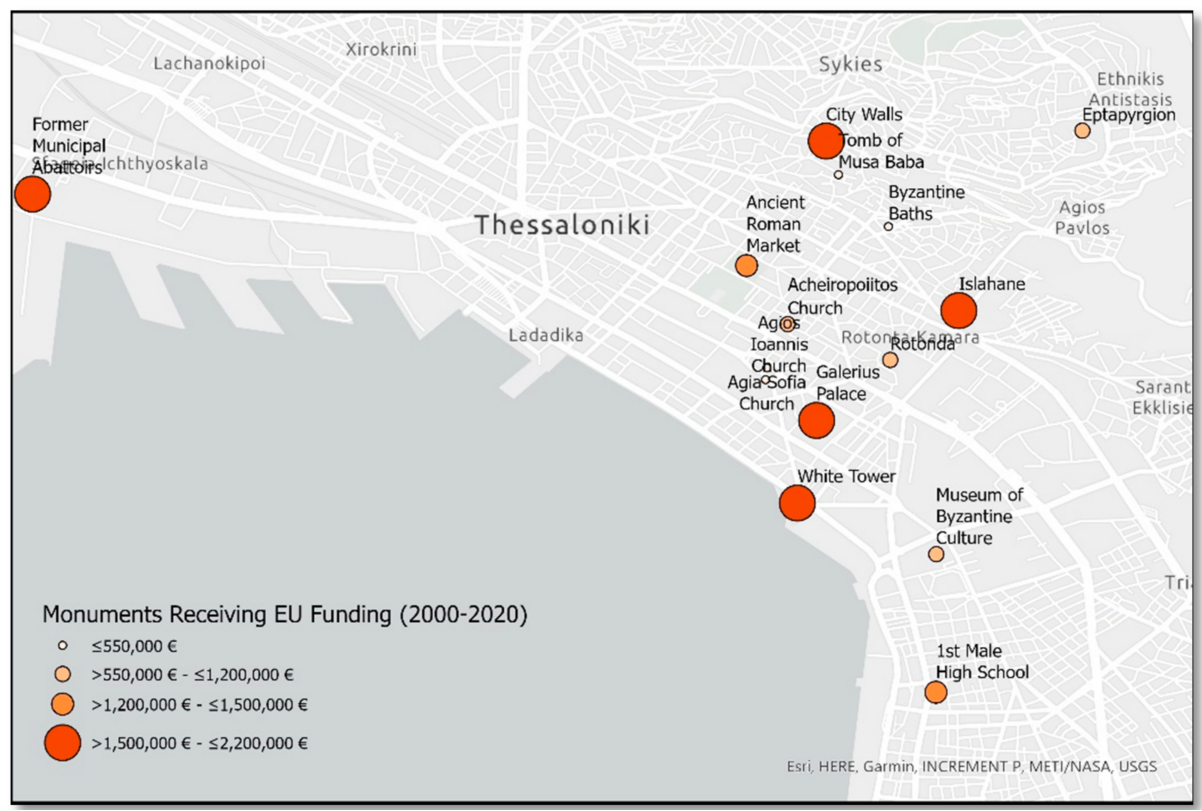

Figure 12. Monuments that have received EU funding for restoration works between 2000-2020.

\section{Discussion}

The current research attempted to present a demo web application for $\mathrm{CH}$ mapping and monitoring at a municipal level, in Thessaloniki, Greece, using essentially existing data resources. The city of Thessaloniki constitutes an ideal case study as its long history 
has resulted in a variety of $\mathrm{CH}$ assets located within its administrative boundaries. The web app has refrained from becoming another simple or even GIS-based registry of $\mathrm{CH}$ assets, even if such an infrastructure does not yet exist at a national or municipal level in the country. Furthermore, the application aimed at presenting data in a visually enhancing and organized manner to all stakeholders involved in $\mathrm{CH}$ management, even the general public, using a dashboard format. Finally, an initial effort was implemented, with regards to Indicator 11.4.1 of the SDGs, to calculate a total cost, in terms of necessary evaluation studies, to assess the $\mathrm{CH}$ assets' structural performance, and proceed to their architectural documentation if, according to the collected data, no such designs were available. Several key issues emerged during the research which regard either technical details (such as data acquisition and organization) or urban/public policy inefficiencies (e.g., increased bureaucracy, lack of communication channels between various authorities, the perception and incorporation of $\mathrm{CH}$ as an integral part of the urban fabric, lack of data reporting in terms of actual numbers about $\mathrm{CH}$ assets, etc.).

Data organization and integration into a common infrastructure are essential in any attempt to build a $\mathrm{CH}$ asset monitoring system. In the case of Greece, several agencies and authorities are involved in $\mathrm{CH}$ management, starting at a central government level and moving down to local government and private interests. However, the protection of cultural heritage is a concrete obligation of the State and, as such, state agencies need real-time access to reliable data regarding all listed monuments. Some degree of data standardization is also essential at a national, European, or even global scale; however, this has proved to be far more challenging for $\mathrm{CH}$ assets than any other type of protected site. It could be argued that every aspect of $\mathrm{CH}$ acts like a double-edged sword, in the sense that the older and more elaborate a monument is, and hence more unique, the more tourism it attracts but at the same time creates a need for a higher level of maintenance (increased cost) with tailor-made technical solutions. Standardization in many aspects of $\mathrm{CH}$ is not a realistic option as every monument is unique. However, the application of new technologies and methods (e.g., terrestrial laser scanning, UAVs, lidar sensors, advanced structural simulation, BIM technology, urban digital twins, etc.) can significantly limit the cost of regular and standardized documentation and monitoring.

Besides the actual 2D or 3D documentation of the $\mathrm{CH}$ assets, there seems to be a lack of current descriptive data regarding their use, ownership status, current condition, exact location in the urban fabric, etc. This data is necessary to incorporate $\mathrm{CH}$ into town planning policies and refrain from studying each monument as an urban island with no connection to the rest of the city. In the present research, this data was retrieved from the cadastral database (as a time snapshot), which could be a viable and low-cost option for several other countries as well. However, in a highly dynamic and competitive space such as major urban centers, timely updates of data are essential, both in terms of database entries, as well as field verification of the monuments' condition. A typical example of these dynamic transformations is presented in Figure 13, showing Hotel "Aigyptos" in Ptolemeon Street, located in Thessaloniki's historic center. The building suffered major structural damages in the 1978 earthquake which led to the collapse of the 3rd floor; it was partially abandoned ever since, and was finally demolished in August 2021. Approximately 30-40 listed buildings are presumed to have been demolished between 2000 and 2020, which may not seem like an initially alarming number, but especially in the case of Thessaloniki where $\mathrm{CH}$ assets are usually found in clusters, this rate can alter the landscape of entire neighborhoods. In that respect, it is also considered paramount to monitor any maintenance work performed at listed buildings by enabling the real-time connection of the database to the municipal building permit registry.

The research proceeded further into calculating a total cost for evaluating the structural performance and capacity of the city's architectural listings. This cost can be used as a benchmark for monitoring Indicator 11.4.1 of the SDGs. The actual qualitative assessment outcome is also essential for several other policy documents regarding the expected level of urban resilience to various hazards. This cost has been calculated per listing so that it could 
be readily available for verification and recalculation in the event of a new restoration permit. It must be noted, however, that access to such financial data (study and construction costs) is not permitted to the general public if no actual legal interest can be established, so this cross-check could only be achieved at an institutional level and not by the current web application.

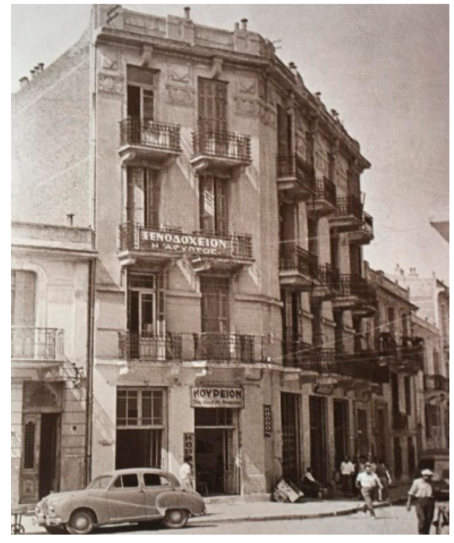

(a)

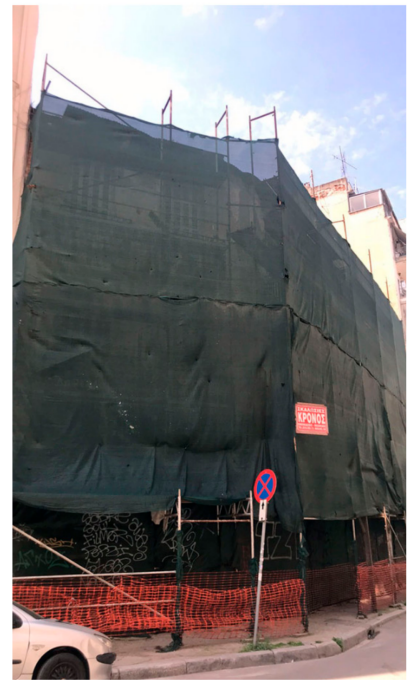

(b)

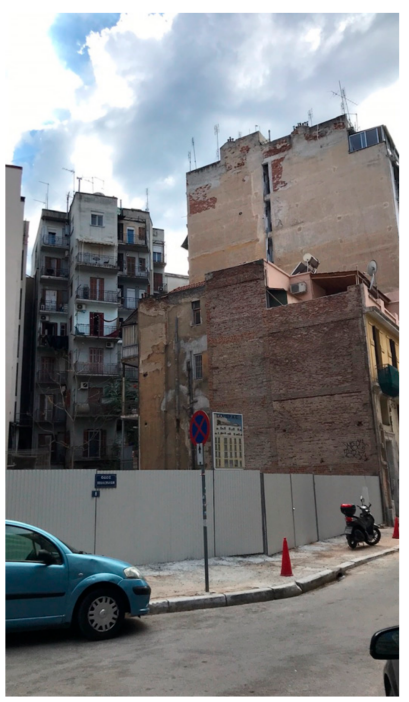

(c)

Figure 13. Hotel "Aigyptos" in Ptolemeon Str. (a) Historic Photo of the building [47] (p. 108); (b) photo in May 2021; (c) photo in September 2021.

With regards to the calculated sum of 70.2 million euros, it corresponds to approximately $215 €$ /per resident (the city recorded a population of 325,182 residents in the census of 2011), which if divided even further, assuming that these assessments will have a nominal life of 10 years, leads to $21 € /$ per resident/per annum. This number can provide a starting point for an extensive discussion on the valorization of $\mathrm{CH}$ by the city's residents and whether we would all be interested in contributing to $\mathrm{CH}$ preservation even in the form of partial subsidization.

\section{Conclusions}

The findings of the present research advocate that it is possible to build effective and visually powerful tools for $\mathrm{CH}$ mapping, monitoring, and reporting using existing, mainly open source, datasets (if available). Open source programming libraries such as Dash Plotly enable the construction and deployment of cross-platform web apps at a minimum cost, thus enhancing the dissemination of information on $\mathrm{CH}$ and the active involvement of key stakeholders.

The limitations of the current research regard the fact that it is essentially a snapshot of the collected data between January and August of 2021 as, for example, no real-time access to the cadastral database can be provided to private parties, even for research purposes. In addition to that, the project is sensitive to any potential registration errors in the datasets that were used. In the event that a similar application was to be deployed by a central or local government authority incorporating CRUD (Create, Read, Update, Delete) operations and cross-institutional communication, then real-time monitoring of $\mathrm{CH}$ assets could effectively be implemented. Furthermore, government authorities through their various agencies and institutions (such as the Building Permit Authorities) have access to private funding spent in each listing and could eventually report back on it for the SDGs.

Perhaps the most crucial topic to be addressed in terms of future research or best practices application is the timely and regular field update of the listings' condition and poten- 
tial structural problems. As was mentioned, the technical and non-technical professionals that are considered to have domain knowledge on $\mathrm{CH}$ maintenance and preservation do not form a critical mass of people that can report on possible hazards. In that respect, the engagement of the general population through a public participation Web GIS application or crowdsourcing data could facilitate the monitoring process. The application of modern documentation technologies such as UAVs is also expected to provide considerable assistance without increasing operational costs.

Finally, the effectiveness of the present demo web application in terms of data representation and visualization will be accessed through a questionnaire that will also try to determine the level of awareness of the city's residents with regards to the listed assets in their neighborhood and throughout the city's urban fabric.

Author Contributions: Conceptualization, S.C., A.A., P.P. and C.G.; methodology, S.C.; software, S.C.; validation, A.A., P.P. and C.G.; formal analysis, S.C., A.A., P.P. and C.G.; resources, S.C.; data curation, S.C.; writing-original draft preparation, S.C., A.A., P.P. and C.G.; writing-review and editing, S.C., A.A., P.P. and C.G.; visualization, S.C. All authors have read and agreed to the published version of the manuscript.

Funding: This research received no external funding.

Institutional Review Board Statement: Not applicable.

Informed Consent Statement: Not applicable.

Data Availability Statement: The data presented in this study are openly available in http:// listedmonuments.culture.gr / (Data on CH listings by the Ministry of Culture, accessed on 5 September 2021), http:/ / www.mathra.gr/ergo-draseis / diatiritea-ktiria-paradosiakoi-oiki/ (Data on CH listings by the Ministry of Interior-Sector of Macedonia and Thrace, accessed 10 May 2021), http:/ / estia.minenv.gr/ (Data on CH listings by the Ministry of the Environment and Energy, accessed on 20 May 2021), http://gis.thessaloniki.gr/sdi (Spatial Data Infrastructure Portal of the Municipality of Thessaloniki, accessed on 10 May 2021), https:/ /opengov.thessaloniki.gr/eypiresies / anazitiseis / poleodomikes-adeies (Building Permits Registry of the Municipality of Thessaloniki, accessed on 25 May 2021), https:/ / www.ktimanet.gr/geoportal/catalog/main/ (Cadastral Parcels spatial information from the "Hellenic Cadastre Agency", accessed on 20 August 2021), https: / www.arxaiologikoktimatologio.gov.gr/ (Archaeological Cadastre GIS portal, accessed on 5 September 2021), https:/ / www.thessheritage.gr/ (Spatially Enabled Web application in a dashboard format created by the authors, accessed on 15 September 2021).

Conflicts of Interest: The authors declare no conflict of interest.

\section{References}

1. UNESCO. Culture for Development Indicators Methodology Manual. 2014. Available online: https://en.unesco.org/creativity/ sites/creativity/files/cdis_methodology_manual_0_0.pdf (accessed on 18 August 2021).

2. Ontario's Ministry of Tourism, Culture and Sport. A Guide to Cultural Heritage Resources in the Land Use Planning Process: Review Draft. 2017. Available online: http://www.downloads.ene.gov.on.ca/envision/env_reg/er/documents/2017/013-0914_ MTCS.pdf (accessed on 8 August 2021).

3. Chiabrando, F.; Colucci, E.; Lingua, A.; Matrone, F.; Noardo, F.; Spanò, A. A European Interoperable Database (Eid) to increase Resilience of Cultural Heritage. ISPRS Int. Arch. Photogramm. Remote Sens. Spat. Inf. Sci. 2018, 42, 151-158. [CrossRef]

4. Carlisle, P.; Lee, E. Recording the past: Heritage inventories in England. J. Cult. Herit. Manag. Sustain. Dev. 2016, 6, 128-137. [CrossRef]

5. Gogolou, C.; Dimopoulou, E. Land Administration Standardization for the integration of cultural heritage in land use policies. Land Use Policy 2015, 49, 617-625. [CrossRef]

6. INSPIRE. D.2.8.I.9 Data Specification on Protected Sites-Technical Guidelines. Available online: https://inspire.ec.europa.eu/ $\mathrm{id} /$ document/tg/ps (accessed on 16 August 2021).

7. Prieto, I.; Izkara, J.L.; Del Hoyo, F.J.D. Efficient Visualization of the Geometric Information of CityGML: Application of the Documentation of Built Heritage; Computational Science and Its Applications-ICCSA 2012; Springer: Berlin/Heidelberg, Germany, 2012.

8. Costamagna, E.; Spanò, A. CityGML for Architectural Heritage. In Developments in Multidimensional Spatial Data Models; Springer: Berlin/Heidelberg, Germany, 2012; pp. 219-237. [CrossRef]

9. Noardo, F. Architectural heritage semantic 3D documentation in multi-scale standard maps. J. Cult. Herit. 2018, 32, 156-165. [CrossRef] 
10. Gkadolou, E.; Prastacos, P.; Loupas, T. Documentation of Cultural Heritage monuments with CityGML: An application for ancient theatres. AGILE GISci. Ser. 2020, 1, 1-16. [CrossRef]

11. Armesto-González, J.; Riveiro-Rodríguez, B.; González-Aguilera, D.; Rivas-Brea, M.T. Terrestrial laser scanning intensity data applied to damage detection for historical buildings. J. Archaeol. Sci. 2010, 37, 3037-3047. [CrossRef]

12. Bakirman, T.; Bayram, B.; Akpinar, B.; Karabulut, F.M.; Bayrak, O.C.; Yigitoglou, A.; Seker, D.Z. Implementation of ultra-light UAV systems for cultural heritage documentation. J. Cult. Herit. 2020, 44, 174-184. [CrossRef]

13. Rodríguez-Gonzálvez, P.; Jiménez Fernández-Palacios, B.; Muñoz-Nieto, Á.L.; Arias-Sanchez, P.; Gonzalez-Aguilera, D. Mobile LiDAR System: New Possibilities for the Documentation and Dissemination of Large Cultural Heritage Sites. Remote Sens. 2017, 9, 189. [CrossRef]

14. Trier, Ø.D.; Reksten, J.H.; Løseth, K. Automated mapping of cultural heritage in Norway from airborne lidar data using faster R-CNN. Int. J. Appl. Earth Obs. Geoinf. 2021, 95, 102241. [CrossRef]

15. Bachagha, N.; Wang, X.; Luo, L.; Li, L.; Khatteli, H.; Lasaponara, R. Remote sensing and GIS techniques for reconstructing the military fort system of the Roman boundary (Tunisian section) and identifying archaeological sites. Remote Sens. Environ. 2020, 236, 111418. [CrossRef]

16. Formisano, A.; Chieffo, N.; Mosoarca, M. Probabilistic damage scenario: A case study in Amatrice affected by the 2016 seismic sequence. In Proceedings of the 3rd International Conference on Protection of Historical Constructions, Lisbon, Portugal, 12-15 July 2017.

17. Ravankhah, M.; Schmidt, M.; Will, T. An indicator-based risk assessment framework for World Heritage Sites in seismic zones: The case of "Bam and its Cultural Landscape" in Iran. Int. J. Disaster Risk Reduct. 2021, 63, 102405. [CrossRef]

18. Comite, V.; Miani, A.; Ricca, M.; La Russa, M.; Pulimeno, M.; Fermo, P. The impact of atmospheric pollution in outdoor cultural heritage: An analytic methodology for the characterization of the carbonaceous fraction in black crusts present on stone surfaces. Environ. Res. 2021, 201, 111565. [CrossRef] [PubMed]

19. Cacciotti, R.; Kaiser, A.; Sardella, A.L.; De Nuntiis, P.; Drdácký, M.; Hanus, C.; Bonazza, A. Climate change-induced disasters and cultural heritage: Optimizing management strategies in Central Europe. Clim. Risk Manag. 2021, 32, 100301. [CrossRef]

20. Bonazza, A.; Sardella, A.; Kaiser, A.; Cacciotti, R.; De Nuntiis, P.; Hanus, C.; Maxwell, I.; Drdácký, T.; Drdácký, M. Safeguarding cultural heritage from climate change related hydrometeorological hazards in Central Europe. Int. J. Disaster Risk Reduct. 2021, 63, 102455. [CrossRef]

21. Research Assessment \& Safeguarding of the Heritage of Iraq in Danger (Rashid). The Intentional Destruction of Cultural Heritage in Iraq as a Violation of Human Rights-Submission for the United Nations Special Rapporteur in the Field of Cultural Rights 2017. Available online: https:/ / zenodo.org/record/3835895\#.YTUBlY4zZPY (accessed on 1 September 2021).

22. Guidetti, M.; Perini, S. Civil War and Cultural Heritage in Syria, 2011-2015. Syrian Stud. Assoc. Bull. 2015, 20, 1-42. Available online: http:/ / ojcs.siue.edu/ojs/index.php/ssa/article/view/3115 (accessed on 1 September 2021).

23. Weiss, T.G.; Connelly, N. Cultural Cleansing and Mass Atrocities, Protecting Cultural Heritage in Armed Conflict Zones, J. Paul Getty Trust Occasional Papers in Cultural Heritage Policy, No. 1. 2017. Available online: https://www.getty.edu/publications/ pdfs/CulturalCleansing_Weiss_Connelly.pdf (accessed on 1 September 2021).

24. EN 1998-3. EN 1998-3: Eurocode 8: Design of Structures for Earthquake Resistance-Part 3: Assessment and Retrofitting of Buildings; CEN (European Committee for Standardization): Brussels, Belgium, 2005.

25. Spyrakos, C.C. Seismic Risk of historic structures and monuments: A need for a unified policy. In Proceedings of the 5th Thematic Conference on Computational Methods in Structural Dynamics and Earthquake Engineering (ECCOMAS), Crete Island, Greece, 6-10 December 2016.

26. Maio, R.; Ferreira, T.M.; Vicente, R. A critical discussion on the earthquake risk mitigation of urban cultural heritage assets. Int. J. Disaster Risk Reduct. 2018, 27, 239-247. [CrossRef]

27. UNESCO. Placing Culture at the Heart of Sustainable Development Policies; Hangzhou Congress on Culture and Development: Hangzhou, China, 2013.

28. UNESCO. Policy Document for the Integration of a Sustainable Development Perspective into the Processes of the World Heritage Convention, General Assembly of States Parties. 2015. Available online: https:/ / whc.unesco.org/document/139747 (accessed on 1 September 2021).

29. Petti, L.; Trillo, C.; Makore, B.N. Cultural Heritage and Sustainable Development Targets: A Possible Harmonisation? Insights from the European Perspective. Sustainability 2020, 12, 926. [CrossRef]

30. UNESCO. Thematic Indicators for Culture in the 2030 Agenda. 2019. Available online: http://uis.unesco.org/sites/default/ files/documents/publication_culture_2020_indicators_en.pdf (accessed on 10 September 2021).

31. UNSC. Revised List of Global Sustainable Development Goal Indicators, United Nations Statistical Commission. Available online: https: / / unstats.un.org/sdgs/iaeg-sdgs/ (accessed on 29 July 2021).

32. UNESCO Institute for Statistics. Tracking Investment to Safeguard the World's Cultural and Natural Heritage-Results of the 2020 UIS Survey on Expenditure on Cultural and Natural Heritage (SDG Indicator 11.4.1). 2021. Available online: http: // uis.unesco.org/sites/default/files/documents/uis_culture_and_heritage_report_2021_web.pdf (accessed on 3 August 2021).

33. Wang, X.; Ren, H.; Wang, P.; Yang, R.; Luo, L.; Cheng, F. A Preliminary Study on Target 11.4 for UN Sustainable Development Goals. Int. J. Geoheritage Parks 2018, 6, 18-24. [CrossRef] 
34. Zuo, C.; Ding, L.; Meng, L. A Feasibility Study of Map-Based Dashboard for Spatiotemporal Knowledge Acquisition and Analysis. Int. J. Geo-Inf. 2020, 9, 636. [CrossRef]

35. Nocca, F. Hybrid Evaluation Tools for Operationalizing UNESCO Historic Urban Landscape Approach; University of Naples Federico II: Naples, Italy, 2017.

36. Nocca, F. The Role of Cultural Heritage in Sustainable Development: Multidimensional Indicators as Decision-Making Tool. Sustainability 2017, 9, 1882. [CrossRef]

37. Montalto, V.; Tacao Moura, C.J.; Langedijk, S.; Saisana, M. Culture Counts: An empirical approach to measure the cultural and creative vitality of European Cities. Cities 2019, 89, 167-185. [CrossRef]

38. Ren, W.; Han, F. Indicators for assessing the sustainability of built heritage attractions: An Anglo-Chinese Study. Sustainability 2018, 10, 2504. [CrossRef]

39. UNESCO. Recommendation on the Historic Urban Landscape; UNESCO: Paris, France; World Heritage Center: Paris, France, 2011.

40. Vyzantiadou, M.M.; Selevista, M. Protection of Cultural Heritage in Thessaloniki. Heritage 2019, 2, 717-731. [CrossRef]

41. European Commission. Communication from the Commission to the European Parliament, the Council, the European Economic and Social Committee and the Committee of the Regions. Towards an Integrated Approach for Cultural Heritage in Europe, Brussels, 22.07.2014; European Commission: Brussels, Belgium, 2014.

42. Foster, G.; Kreinin, H.; Stagl, S. The Future of circular environmental impact indicators for cultural heritage buildings in Europe. Environ. Sci. Eur. 2020, 32, 141. [CrossRef]

43. Dash by Plotly Online Documentation. Available online: https://dash.plotly.com/ (accessed on 1 September 2021).

44. Ambiente Italia Research Institute. European Common Indicators (ECI): Towards a Local Sustainability Profile; Final Project Report; Office for Official Publication of the European Communities: Luxemburg, 2003. Available online: https://www.gdrc.org/uem/ footprints/eci_final_report.pdf (accessed on 10 August 2021).

45. Economist Intelligence Unit (EIU). Benchmarking Global City Competitiveness (GCI). The Economist, 2012. Available online: https://www.citigroup.com/citi/citiforcities/pdfs/eiu_hotspots_2012.pdf (accessed on 14 August 2021).

46. de Medellin, A. Indicadores urbanos para America Latina y Caribe: Una propuesta Para la Evaluación de Políticas Publicas. 2009. Available online: https://www.medellin.gov.co/irj/go/km/docs/wpccontent/Sites/Subportal\%20del\%20Ciudadano/ Planeaci\%C3\%B3n\%20Municipal/Secciones/Publicaciones/Documentos/Indicadores\%20Urbanos/INDICADORES\%20 URBANOS.pdf (accessed on 3 September 2021).

47. Kolonas, V. A Hundred Years of Hospitality —The Hotels of Thessaloniki (1914-2014); University Studio Press: Thessaloniki, Greece, 2015; ISBN 978-960-12-2245-5. (In Greek and English) 